듬 SCHOOL of GRADUATE STUDIES

EAST TENNESSEE STATE UNIVERSITY
East Tennessee State University Digital Commons@ East Tennessee State University

$5-2013$

\title{
Assessment of Dietary Behaviors of College Students Participating in the Health Promotion Program BUCS: Live Well
}

Courtney E. McKinney

East Tennessee State University

Follow this and additional works at: https://dc.etsu.edu/etd

Part of the International and Community Nutrition Commons, and the Nutritional Epidemiology Commons

\section{Recommended Citation}

McKinney, Courtney E., "Assessment of Dietary Behaviors of College Students Participating in the Health Promotion Program BUCS: Live Well" (2013). Electronic Theses and Dissertations. Paper 1105. https://dc.etsu.edu/etd/1105

This Thesis - Open Access is brought to you for free and open access by the Student Works at Digital Commons @ East Tennessee State University. It has been accepted for inclusion in Electronic Theses and Dissertations by an authorized administrator of Digital Commons@ East Tennessee State

University. For more information, please contact digilib@etsu.edu. 
Assessment of Dietary Behaviors of College Students Participating in the Health Promotion Program BUCS: Live Well

\author{
A thesis \\ presented to \\ the faculty of the Department of Allied Health Sciences \\ East Tennessee State University
}

In partial fulfillment

of the requirements for the degree

Master of Science in Clinical Nutrition

by

Courtney McKinney

May 2013

\author{
Michelle Lee, PhD, RD, Committee Chair \\ Eileen Cress, MS, RD, Committee Member \\ Elizabeth Lowe, MS, RD, Committee Member
}

Keywords: College Student, Emerging Adulthood, Online Health Promotion Program, Dietary Habits, Obesity, Weight Gain 


\begin{abstract}
Assessment of Dietary Behaviors of College Students Participating in the Health Promotion Program BUCS: Live Well

by

Courtney McKinney

Rates of adult obesity in the United States continue to rise, especially among the college-age population who typically practice poor dietary choices, contributing to weight gain. College-age students experience a transitional phase called 'emerging adulthood' where they learn autonomy in many areas that influence long-term health status. The purpose of the online health promotion program BUCS: Live Well was to promote self-efficacy in ability to incorporate positive dietary changes, assess incidences of positive dietary habits after completing the program, and determine if weight status, residence, and health perceptions influence dietary behaviors. BUCS: Live Well was successful in assessing current dietary intake, facilitating positive dietary changes, and improving self-efficacy about incorporating positive dietary changes, although it did not promote weight loss. Online health promotion programs for college students are effective in initiating lifestyle modification and need to be available in hopes of reducing the obesity rate in this population.
\end{abstract}




\section{ACKNOWLEDGEMENTS}

My sincerest thanks gratitude to all of those who helped make this thesis a reality, especially:

Dr. Michelle Lee for allowing me to partner with your research and use part of it for my thesis despite the extra work involved. Thank you for keeping me focused on getting the job done and encouraging me to keep realistic expectations. I appreciate the extended hours you gave me to work through the details. Your enthusiasm made conducting the research fun and valuable. Thank you for teaching me to love research in a way I can carry into professional practice.

Mrs. Elizabeth Lowe and Mrs. Eileen Cress for your patience in reviewing my manuscripts and your diligent attention to detail. Thank you for providing outside perspectives that improved the quality of discussion section.

Dr. Kitty Coffey and Dr. Kimberly Johnson for encouraging me to complete a thesis even before I knew I would attend graduate school. Your belief in me from the beginning of my dietetics education has pushed me to where I am today.

My family, friends, and fellow interns who supported me every step of the way. I could not have completed this without your understanding of all the time I gave to my thesis. Thank you for your and prayers and positive words as you encouraged me to succeed.

My God, the Creator of the human body who designed the intricate relationship between diet and health that we call nutrition. "The fear of the Lord is the beginning of knowledge," Proverbs 1:7. 


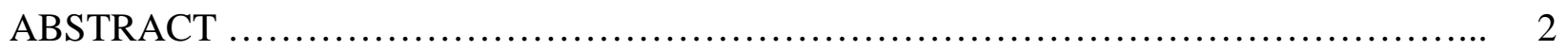

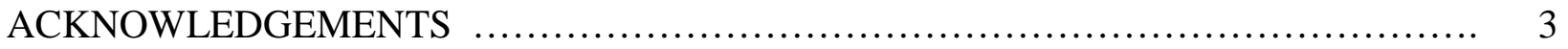

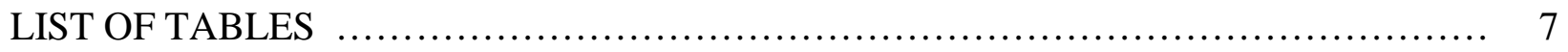

\section{Chapter}

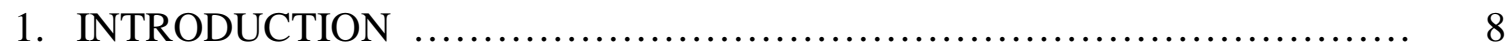

Health Related Lifestyle Practices of College Students $\ldots \ldots \ldots \ldots \ldots \ldots \ldots \ldots . \quad 8$

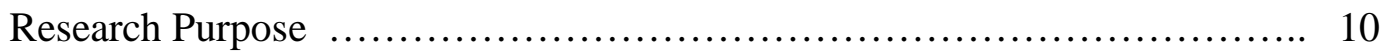

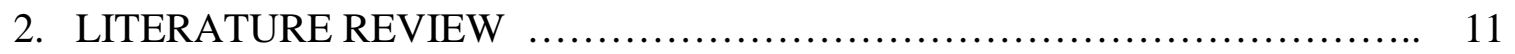

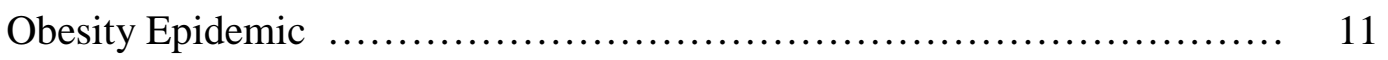

Obesity Rates in the United States $\ldots \ldots \ldots \ldots \ldots \ldots \ldots \ldots \ldots \ldots \ldots \ldots . \ldots \ldots$

Obesity Among College Students $\ldots \ldots \ldots \ldots \ldots \ldots \ldots \ldots \ldots \ldots \ldots \ldots \ldots \ldots$

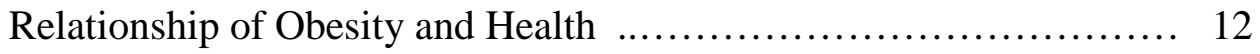

College Student Behaviors Support Obesity Development ........... 12

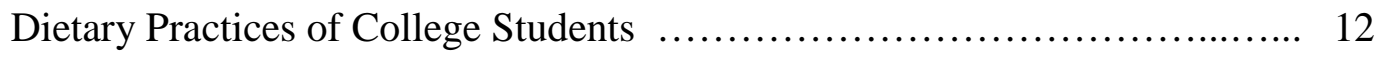

Change of Dietary Patterns and Nutrient Consumption $\ldots . \ldots \ldots \ldots \ldots . . . .12$

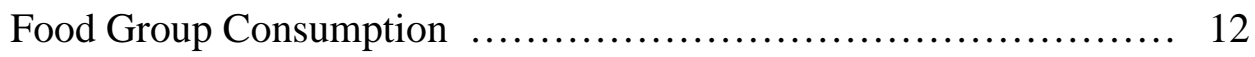

Implications of Dietary Patterns of College Students $\ldots \ldots \ldots \ldots \ldots \ldots . . \ldots 14$

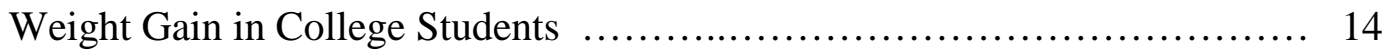


Factors Affecting Weight Gain in College Students

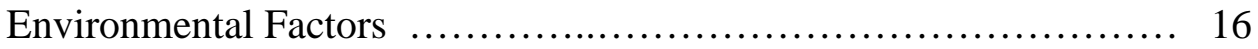

Barriers and Enablers to Weight Management $\ldots \ldots \ldots \ldots \ldots \ldots \ldots \ldots . \ldots 17$

Student Preparedness for Transition to College $\ldots \ldots \ldots \ldots \ldots \ldots \ldots . . . \ldots 18$

Residence of College Students $\ldots \ldots \ldots \ldots \ldots \ldots \ldots \ldots \ldots \ldots \ldots \ldots \ldots \ldots . \ldots \ldots \ldots$

Other Factors Influencing Weight Gain $\ldots \ldots \ldots \ldots \ldots \ldots \ldots \ldots \ldots \ldots$

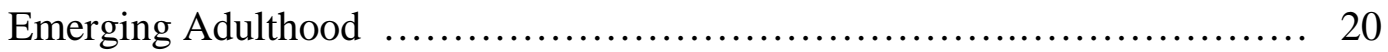

Description of Emerging Adulthood f........................... 20

Significance of Emerging Adulthood on Dietary Patterns ........... 20



Nutrition Intervention Programs on University Campuses $\ldots . \ldots \ldots \ldots \ldots \ldots \ldots . .23$

Traditional Nutrition Intervention Programs $\ldots \ldots \ldots \ldots \ldots \ldots \ldots \ldots . \ldots 23$

Online Nutrition Intervention Programs $\ldots \ldots \ldots \ldots \ldots \ldots \ldots \ldots \ldots . \ldots . \ldots 23$

Alternative Nutrition Intervention Programs $\ldots \ldots \ldots \ldots \ldots \ldots \ldots \ldots . . \ldots 25$

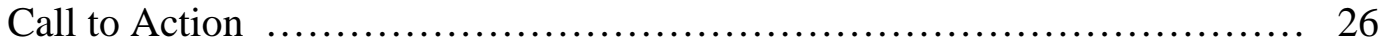

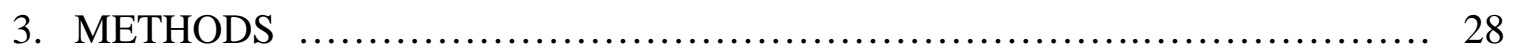

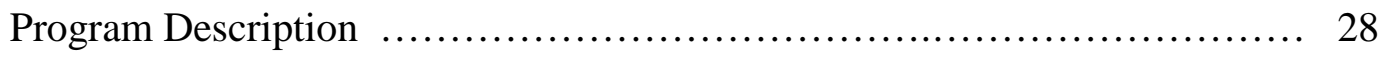



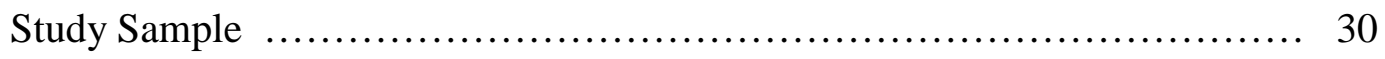




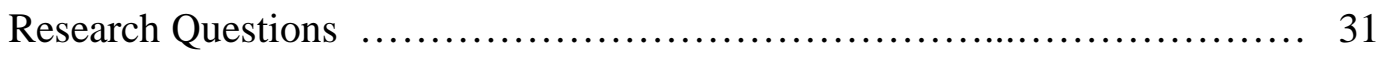

Institutional Review Board Approval.................................... 32

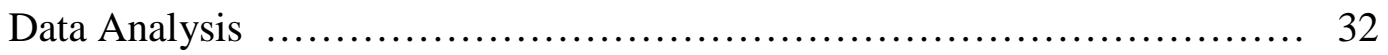

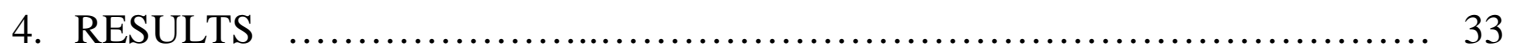

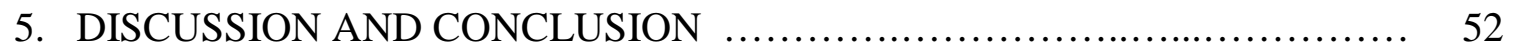

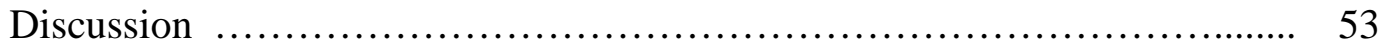

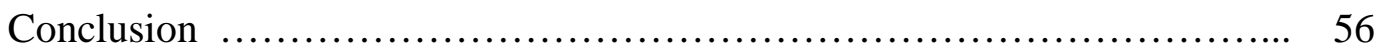

REFERENCES .......................................................... 57

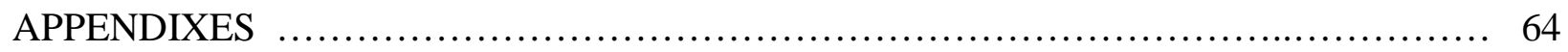

Appendix A: Informed Consent Form and Preevaluation Questionnaire: Control ..... 64

Appendix B: Informed Consent Form and Preevaluation Questionnaire: Intervention .. 71

Appendix C: Informed Consent Form and Postevaluation Questionnaire: Control ....... 78

Appendix D: Informed Consent Form and Postevaluation Questionnaire: Intervention. 85

Appendix E: Food Frequency Questionnaire Tables ........................... 94

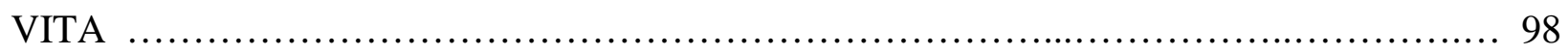




\section{LIST OF TABLES}

Table

Page

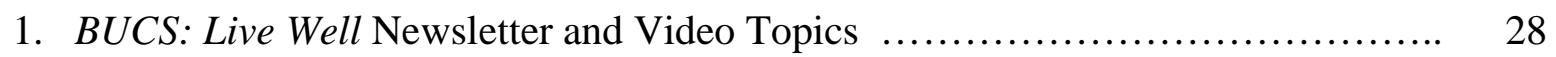

2. Demographics of Participants of BUCS: Live Well .......................... 33

3. BMI, Weight, Waist Circumference, and Body Fat Percentage Measurements of

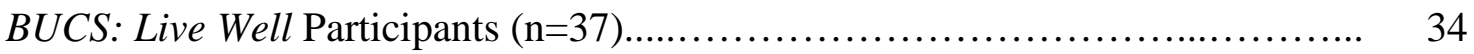

4. BMI of Initial and Final BUCS: Live Well Participants ....................... 35

5. Self-Perception of Initial and Final Participants of BUCS: Live Well ........... 36

6. Weight Perception Survey Responses of BUCS: Live Well Participants ........... 38

7. Diet Habit Survey Responses of BUCS: Live Well Participants (n=37) ........... 39

8. Paired Samples t-tests Preevaluation and Postevaluation of Confidence Survey Questions of BUCS: Live Well Final Control Participants ............... 40

9. Paired Samples t-tests Preevaluation and Postevaluation of Confidence Survey Questions of BUCS: Live Well Final Intervention Participants............. 41

10. Fruit, Vegetable, Salt, and Fat Intake of All BUCS: Live Well Participants that

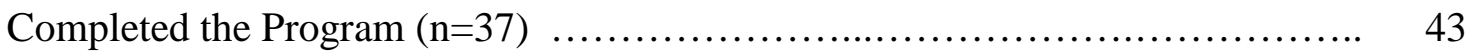

11. Correlations of Final BUCS: Live Well Participants $(n=37) \quad \ldots \ldots \ldots \ldots \ldots \ldots \ldots . . . \ldots 6$

12. Correlations of BUCS: Live Well Intervention Group Participants $(n=19) \ldots \ldots \ldots . \quad 48$

13. Correlations of BUCS: Live Well Control Group Participants $(n=18) \ldots \ldots \ldots \ldots \ldots .49$

14. Survey Response on Program Success from BUCS: Live Well Intervention Final

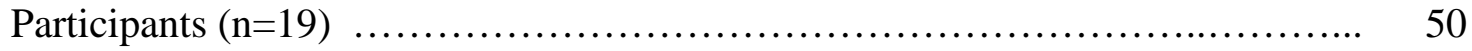




\section{CHAPTER 1}

\section{INTRODUCTION}

\section{$\underline{\text { Health Related Lifestyle Practices of College Students }}$}

Obesity is a rising epidemic in the United States affecting $35.5 \%$ of adult men and $35.8 \%$

of adult women. ${ }^{1}$ In the $18-29$ year old or college-age population, $36.7 \%$ are overweight or obese. $^{2}$ The college-aged population has the greatest increase in obesity rates over any other American population. ${ }^{2}$ During the transition from adolescence to young adulthood, a higher proportion of individuals become and remain obese when compared to other age-based populations. $^{3}$ The 18-29 year old age range encompasses this transition period and includes more than 10 million full-time college students. ${ }^{4}$

In addition to obesity, college students are demonstrating other unhealthy behaviors such as poor fruit and vegetable intake and decreasing amounts of exercise. The American College Health Association reported that only 7\% of 3,718 college students ate 5 or more fruits and vegetables daily and $43.6 \%$ reported vigorous exercise for 20 minutes or moderate exercise for 30 minutes 3 or fewer days of the week. ${ }^{5}$ According to the Surgeon General, a key determinant of one's health status is nutritional intake, because dietary factors are associated with 5 of the 10 leading causes of death in the United States. ${ }^{6}$ The dietary practices of college students are significant because of their potential influence on long-term health status in the future. Obese individuals are at increased risk of developing diabetes mellitus, cardiovascular disease, hypertension, strokes, and possibly cancer. ${ }^{7,8}$ The onset of these diseases could be prevented through the prevention of obesity in the college-age population.

Numerous research findings report various conclusions about the amount of weight gained during the college years and specifically the first semester of college. Research indicates 
that college students demonstrate a significant weight gain, approximately 9 pounds, between their freshman and sophomore years. ${ }^{9,}{ }^{10}$ Additional research shows that college students can gain 1.3 to 3.1 kilograms $(\mathrm{kg})$ or 2.68 to 6.82 pounds (lbs) within the first semester of freshman year. ${ }^{11}$ Some studies have even claimed to confirm the 'freshman 15 ' as fact. ${ }^{12}$

Many factors could contribute to the weight gain of college students. Understanding the influences of student behavior may help prevent the increasing obesity rates among college students. ${ }^{13}$ Environmental, behavioral, and occupational changes contribute to the college student's weight gain. ${ }^{11}$ The strongest factors that predict college weight gain are identified as residency, dietary restraint, and decreased physical activity. ${ }^{11}$ Students believe that the unhealthful foods served in their on-campus cafeterias make it easy to overeat and difficult to maintain a healthy weight. ${ }^{14}$ Living arrangements can influence a student's dietary practices, if the student knows how to choose and prepare healthy foods with the ability to do so on a regular basis. ${ }^{15}$ Students preparing to enter college may not have the skill set necessary to maintain a healthy weight. ${ }^{10}$

The college student population is a unique group that requires the specific attention of the dietetics professional. The lifestyle patterns students learn during their college years can predispose them to future health problems associated with overweight and obesity. ${ }^{9}$ Students in ‘emerging adulthood' (age classification of 18-25 years old) have increasing independence and autonomy; this is where lasting health behavior patterns are developed. ${ }^{16,17}$ Times of transition, such as leaving home and increased decision-making power while still being financially dependent, define many in the 'emerging adulthood' group. ${ }^{17}$ In addition, this population may not have adequate self-regulatory skills, such as planning and self-monitoring, to maintain healthful behaviors in the college environment. ${ }^{10}$ 
Little attention has been given to healthy eating behaviors for this 'emerging adulthood' population. ${ }^{16}$ Although interventions have been attempted, many students continue to consume unhealthy foods. Academic institutions use traditional classroom settings, online class settings, and other creative means to implement nutrition intervention among college students. Providing students with information about healthy choices, even at point-of-purchase, is not enough to influence positive dietary choices. ${ }^{18}$ Understanding the dietary patterns of this population is essential in creating effective behavior change interventions. ${ }^{19}$

\section{$\underline{\text { Research Purpose }}$}

The health promotion program BUCS: Live Well, was designed to determine the attitudes of college students concerning their health, the typical dietary practices of this population, and what nutrition education and counseling methods are effective in changing these attitudes and practices in a positive way. This is a sensitive population experiencing possibly the last opportunity to receive formal education about nutrition and healthy lifestyles. Influencing this population to incorporate a healthy lifestyle could help decrease the nation's obesity rate, childhood obesity rates, and many comorbidities associated with adult and childhood obesity. The purpose of this study was to determine if BUCS: Live Well, designed on principles of the social cognitive theory and self-efficacy, provides college students with the education and motivation needed to implement positive dietary changes. This program will equip students with the needed skills to improve their confidence level to incorporate positive dietary habits. Positive dietary habits include consuming adequate amounts of fruits and vegetables and actively trying to avoid high salt and fat foods. Positive dietary habits will also be measured by how often healthy food choices are consumed as reported in the food frequency questionnaire. 


\section{CHAPTER 2}

\section{LITERATURE REVIEW}

\section{Obesity Epidemic}

\section{Obesity Rates in the United States}

Obesity is an American epidemic. Americans have higher obesity rates than Canada or England-rates that have doubled in the last 50 years. ${ }^{1,20}$ Increases in the prevalence of obesity and body mass index (BMI) occurred between 1980 and 1999 leading to 2009-2010 data that indicate that $35.5 \%$ of adult men and $35.8 \%$ of adult women are obese, with a BMI equal to or greater than 30, as defined by weight $(\mathrm{kg}) /$ height $\left(\mathrm{m}^{2}\right) .{ }^{1}$ The prevalence of obesity in adults in the United States continues to exceed $30 \%$ in most sex-age groups. ${ }^{1}$ This increase in obesity and overweight status of individuals is apparent among both adults and children. ${ }^{13}$

\section{Obesity Among College Students}

The transition from adolescence to young adulthood is a time where a higher than normal proportion of this age group becomes and remains obese. ${ }^{3}$ Obesity seems to be increasing most rapidly among adults in the 18-29 year old age group. ${ }^{21}$ This age range includes more than 10 million full-time college students. ${ }^{4}$ According to research from 2011, 32\% of college students entering college are in the overweight or obese categories with elevated body mass indexes. ${ }^{22}$ The American College Health Association reports 37.6\% of college students are overweight or obese based on their own self-reported weight. ${ }^{23}$ College students may have a higher rate of obesity than their peers not attending college. ${ }^{21}$ According to data through 2010 from the American Medical Association, 33.2\% of men and 31.9 \% of women ages 20-39 of all racial groups had a BMI equal to or greater than 30 as defined by $\mathrm{kg} / \mathrm{m}^{2}{ }^{1}$ 


\section{$\underline{\text { Relationship of Obesity and Health }}$}

The Surgeon General states that a key determinant of one's health status is nutritional intake because dietary factors are associated with 5 of the 10 leading causes of death in the United States. ${ }^{6}$ Obese individuals are at risk for a decreased quality of life because of their increased risk of developing diabetes mellitus, cardiovascular disease, hypertension, strokes, and possibly cancer. ${ }^{7,8}$ Even those who are at the higher end of the normal BMI range may be at increased risk for developing these diseases. ${ }^{24}$ These outcomes may develop later in life even though the cause can develop in the transition from adolescence to adulthood. ${ }^{13}$ Problems that are not health-related may also occur as a result of obesity. According to the Center for Disease Control, obesity also lowers self-esteem and hinders academic performance. ${ }^{25}$

\section{College Student Behaviors Support Obesity Development}

Physical activity and weight status are 2 of the leading indicators to assess an individual's health. Data from the National College Health Assessment and the College Health Risk Behavior Survey reveal that overall the college student population does not meet the recommendations of physical activity or maintaining a healthy weight status. ${ }^{4}$ The Healthy People 2010 goals for the nation's health specifically include a reduction in the prevalence of obesity for this college-aged population. $^{26}$

\section{Dietary Practices of College Students}

\section{Change of Dietary Patterns and Nutrient Consumption}

Dietary changes occur during a college student’s freshman year as they transition from adolescence to young adulthood. The dietary changes could be partially due to the buffet-style dining halls many students have access to. ${ }^{25}$ Diet quality also changes during this time period, resulting in college students not meeting the recommended dietary guidelines. ${ }^{27}$ The diet of most 
college students is typically lacking in fruit, vegetable, and dairy consumption but is high in fat, sodium, and sugar. College students also have limited food variety, high snacking frequency, high incidence of meal skipping for weight loss, and a high consumption of fast foods. ${ }^{28}$ Poor consumption of fruit, vegetables, and dairy products, diets lacking in nutrient quality, and sporadic meal patterns increase nutritional risk and unwanted weight gain. ${ }^{28}$ The diets of college students tend to be high in fat, saturated fat, cholesterol, and sodium while they are low in fiber; vitamins A,C, and E; folate; iron; and calcium. ${ }^{29}$

\section{$\underline{\text { Food Group Consumption }}$}

The reported fruit and vegetable consumption of college students is lower than the recommended guidelines according to several studies. One study found the daily fruit and vegetable consumption of college students is between 2.1 and 5.5 servings when the recommendation encourages 9 servings each day. ${ }^{29}$ In a survey of 6,727 students conducted by the American College Health Association, only 8.5\% of the students reported eating 5 or more servings of fruits and vegetables daily. A serving was defined as one medium piece of fruit; onehalf cup cooked or canned fruits or vegetables; three-fourths cup fruit or vegetable juice; a small bowl of salad greens; or one-half cup dried fruit. ${ }^{30}$ Greaney inferred that only $5.7 \%$ of college students report eating 5 or more daily servings of fruits and vegetables, $62 \%$ report only 1 to 2 daily servings of fruits and vegetables, and $21.8 \%$ report eating 3 or more high-fat fat food items a day based on national surveys. ${ }^{14}$ College students also practice poor dietary habits in other areas. Regular consumption of fast-foods is positively associated with higher fat intake in college students. ${ }^{31}$ During this time period, the consumption of soft drinks also increases. ${ }^{32}$ Wengreen reported that college students eat breads/pasta, milk, and meat less frequently than before. ${ }^{23}$ The study of the college student's diet is imperative to understanding the health of the college 
student. Pliner et al. used a 69-item Food Frequency Questionnaire and found that a low consumption of fruits and vegetables was the only dietary predictor of weight gain. ${ }^{33}$ $\underline{\text { Implication of Dietary Patterns of College Students }}$

Racette reported that $71 \%$ of students at both the freshman and senior class levels failed to meet recommendations for fruit and vegetable intake, implying that dietary practices of college students do not improve with age or education level. ${ }^{9}$ A majority of the students (70\%) consumed fewer than 5 fruits and vegetables daily and more than $50 \%$ ate fried or fast foods at least 3 times during the previous week at the beginning of their freshman year. ${ }^{9}$ Although this study did not prove significant dietary practices associated with this weight gain, $71 \%$ of the students had gained weight by their sophomore year. ${ }^{9}$ Because the college years are a time of significant lifestyle change, food patterns established during college are likely to be maintained into adulthood and may have long-term influence on the student's future health and the health of that student's future family. ${ }^{34}$ Lifestyle decisions and dietary choices of young adulthood may have long-term health implications into adulthood. ${ }^{35}$

\section{$\underline{\text { Weight Gain in College Students }}$}

Adults experience the most rapid weight gain during their 20 s. $^{36}$ This age period occurs during the transition from high school to college where many individuals may experience weight gain. ${ }^{24}$ Multiple studies report various amounts of weight gain in the college student population. One study reveals that the number of adolescents becoming and remaining obese as adults is on an upward trend that will probably continue. ${ }^{3}$

Racette reported that $70 \%$ of the students gained $4.1 \mathrm{~kg} \pm 3.6 \mathrm{~kg}$ or $9.02 \pm 7.92 \mathrm{lbs}$ from their freshman to sophomore year. ${ }^{9}$ A study of college students over the traditional 4-year time period reveals that the average weight gain for these students was $0.4 \mathrm{~kg}(0.9 \mathrm{lbs})$ per year in 
females and $1.1 \mathrm{~kg}$ (2.3 lbs) per year in males. This weight gain is statistically significant. ${ }^{4}$ The increased rate of overweight status and obesity for upperclassman is statistically significant but the most rapid portion of weight gain occurrs during the freshman year. ${ }^{4,13}$

Vella-Sarb looked at freshman weight gain specifically with the average weight gain being 4 pounds over the course of 3 to 12 months. ${ }^{37}$ This amount of weight gain sounds small, but is it 2 to 3 times greater than that found in the adult population. ${ }^{38}$ Modest yet statistically significant weight gain does occur specifically during the freshman year of college. ${ }^{39}$ Research also indicates that most of the freshman year weight gain occurs during the first semester of college ${ }^{40}$ Wenegreen et al. state the average weight gain during the first semester of college is 1.3 to $3.1 \mathrm{~kg}$ or 2.86 to $6.82 \mathrm{lbs} .^{23}$ Wengreen also finds that the average amount of weight gained by freshmen during their first semester is $1.5 \mathrm{~kg}$ ( $3.3 \mathrm{lbs}$ ) and shows that $23 \%$ of the study's participants gained $5 \%$ of their baseline body weight or more with an average weight gain of $4.52 \mathrm{~kg}(9.94 \mathrm{lbs}) .{ }^{23}$ Crombie looked at 4 different studies that assessed weight gain during the first semester of college and concluded that the mean weight increase ranges from $1.3 \mathrm{~kg}$ to 3.1 $\mathrm{kg}$ or 2.86 to $6.82 \mathrm{lbs}$. Studies looking at both semesters of freshman year showed an overall weight change from $0.7 \mathrm{~kg}$ to $2.4 \mathrm{~kg}$ (1.54 to $5.28 \mathrm{lbs}) .{ }^{11}$ It is important to note that one study found no weight gain during this particular population's freshman year. ${ }^{41}$

Controversy exists over whether or not college life promotes inappropriate weight gainsome researchers claim to verify the 'freshman 15' while others support evidence that it is a myth. ${ }^{4}$ It is reported that the 'freshman 15 ' is a myth that has spread across campuses due to overeating in buffet-style cafeterias, lack of exercise, and making poor food choices. ${ }^{25}$ This study found that the typical weight gain of college students is less than 15 pounds. ${ }^{25}$ An opposing study 
claims to verify the freshman 15 due to the significant amount of weight gain measured for the first 3 months of college and projecting that this weight gain will continue to progress. ${ }^{12}$

The amount of weight gain during the college years is possibly not as significant as it initially seems. One study reported an average weight gain of 7 pounds indicating that students had an excess of 112 kilocalories a day over the study period. This implies that even a moderate imbalance between energy intake and energy expenditure results in a considerable increase in body weight and fat mass. ${ }^{25}$ If a small change can produce this weight gain, a small change could also prevent it and begin reversing the weight gain. ${ }^{25}$ Preventing excess weight gain in early adulthood may help prevent future health consequences of overweight and obesity. ${ }^{14}$

\section{Factors Affecting Weight Gain in College Students}

\section{$\underline{\text { Environmental Factors }}$}

College students have the challenging task of adapting their behaviors to a new environment in order to maintain their health and nutritional status. ${ }^{42}$ Environmental, behavioral, and occupational changes contribute to the college student's weight gain. ${ }^{11}$ An understanding of environmental influences on student behavior may help prevent the obesity epidemic. ${ }^{13}$ Research indicates that the transition between high school and college creates an environment that supports weight gain. ${ }^{23}$ Eating in dining halls provides access to a greater abundance and variety of foods. This may be a significant risk factor for weight gain if the student consumes food in excess of his or her energy needs. ${ }^{12}$ The increased academic pressures and change in family support bring stress to the college student in transition which impacts weight gain. ${ }^{40,43}$ Crombie also concluded that strong predictors of college weight gain are residency, dietary restraint, and decreased physical activity. ${ }^{11}$ 


\section{Barriers and Enablers to Weight Management}

Greaney et al. studied online focus groups among 8 universities in 8 different states, identifying some barriers and enablers to healthful weight management through discussion questions. These students identified more barriers than enablers for maintaining a healthy weight. Students identified the barriers to not eating healthy food as: limited time, reliance on unhealthy foods, and limited knowledge about healthy foods. Temptation, lack of discipline, and being bored were reported as contributing to unhealthy eating. The participants also felt that the unhealthful foods served at university cafeterias increased the difficulty of eating healthy, maintaining a healthy weight, and not overeating. Students believed purchasing healthy foods was expensive, which hindered them from eating healthy. Participants stated that eating in moderation, watching portion size, and not exceeding a daily calorie limit were the choices required to regulate food intake and maintain a healthy weight. ${ }^{14}$

A comprehensive approach found many factors that affect weight gain during college. Self-esteem is a predictor of weight gain among college freshman. ${ }^{15}$ The transition from living on campus to off campus could be a positive or negative influence on nutritional status. ${ }^{15}$ The health implications of living on campus or off campus and cooking for oneself are determined by the individual. For some, having control over shopping and preparing meals, in addition to the variety of food found in the grocery store, enabled them to eat healthier. For others, living off campus meant purchasing more fast foods or convenience foods, which does not contribute to healthy eating. ${ }^{15}$ Self-regulatory skills, self-control over consumption, and time-management skills were common influencers of eating behaviors. ${ }^{15}$ 


\section{Student Preparedness for Transition to College}

Students may not come into college equipped to make the decisions necessary to maintain a healthy weight and nutritional status. Those entering college may not have adequate self-regulatory skills such as planning and self-monitoring to maintain healthy behaviors during the college years. ${ }^{10}$ High school students may have insufficient knowledge to prevent weight gain. Matvienko found $83 \%$ of high school students knew that excess energy was stored as fat but $25 \%$ did not know where energy came from. ${ }^{24}$ When assessing student's knowledge about nutrition, Searles found that $43 \%$ recognized dietary fat as more energy dense than carbohydrate and protein, $27 \%$ realized body fat is essential for health, and less than $22 \%$ knew the number of calories needed to be expended to lose one pound of fat. ${ }^{44}$ In high school higher critical thinking skills such as problem solving are seldom addressed. Critical thinking is necessary to understand how biology and nutrition interact in relation to body weight. Most teenagers learn about nutrition without understanding its implications to health. ${ }^{24}$ Because many students in this age population are ill-prepared for meal preparation, they often eat in less traditional meal settings. ${ }^{16}$ High school students are aware of the 'freshman 15' and the potential weight gain during college. However, they are not prepared to meet the challenges of preventing weight gain. ${ }^{45}$

The students with more stability in their health behaviors had active lifestyles and more responsibility for meal preparation before entering college. ${ }^{46}$ Students may also be better prepared for these lifestyle changes in college if they participated in regular family meals during childhood and adolescence. ${ }^{17}$ The frequency of family meals during adolescence predicts high intakes of fruit, vegetables, and dark green and orange vegetables and lower intakes of soft drinks during young adulthood. ${ }^{47}$ 


\section{$\underline{\text { Residence of College Students }}$}

Conflicting research exists about whether residence influences dietary intake and lifestyle factors of the college student. ${ }^{28,48}$ Students who live off campus consume less fruit, vegetables, and dairy products, which may indirectly increase their health risks of weight-related diseases. ${ }^{28}$ Brevard found that triglyceride levels are higher in students who live off campus than those who live on campus. ${ }^{49}$ One advantage to living on campus is the variety of food choices that do not require preparation through the on-campus dining facilities. Off-campus students often have to purchase and prepare their foods, which they may be ill equipped to do. ${ }^{28}$ Even those students living with their parents are at risk for poor dietary intake. ${ }^{16}$ Meals provided by the university could play an important role in giving students access a variety of healthy foods. ${ }^{16}$ Posting nutrition information about the foods served in these on-campus dining facilities however does not ignite a change in a college student's dietary choices. ${ }^{18}$

\section{Other Factors Influencing Weight Gain}

The classification year of the college student does not appear to be a factor in determining dietary choices. ${ }^{50}$ There are no differences in fruit and vegetable intake between genders, residence, and number of years in college. ${ }^{29}$ The student's perception of his or her diet is associated with dietary behavior. ${ }^{19}$ This indicates that students have an overall knowledge of what is a healthy diet and whether or not they follow it. Larson conducted a study to determine what factors influence fruit and vegetable intake during 'emerging adulthood'. These factors were: favorable taste preferences, few perceived time barriers to healthy eating, and higher home availability of fruits and vegetables. ${ }^{51}$ College students often struggle with time management among the commitments of academic responsibilities, work, and involvement in extracurricular and social activities. Because of this, students decrease their participation in physical activity and 
look for meals that are fast, convenient, and inexpensive. These food choices are not usually the most nutritious options. Therefore, it is important for universities to offer healthy foods that are also fast, convenient, and inexpensive. ${ }^{15}$

Although the college environment presents many challenges, it also provides many opportunities to impact the physical activity, nutrition, and healthy weight management of college students in a positive way. ${ }^{52}$ Consideration of these factors is critical for the development of effective weight gain prevention strategies during the college freshman year. ${ }^{40}$

\section{Emerging Adulthood}

\section{Description of 'Emerging Adulthood'}

'Emerging adulthood' is a term that can be used to better describe the transitional period of the college-aged student. 'Emerging adulthood' is neither adolescence nor young adulthood but is distinct from them both. This population has independence from many of the social roles associated with adulthood. ${ }^{53}$ Here, an individual is not dependent like a child or responsible like an adult but rather somewhere in between. ${ }^{53}$ 'Emerging adulthood' is defined as ages 18 to 25 years where independence and autonomy are increasing. ${ }^{16}$ This is the age where many individuals are attending college, which then becomes a key transitional period. ${ }^{53}$ There is greater lifestyle freedom in 'emerging adulthood' than ever before. ${ }^{14}$

\section{$\underline{\text { Significance of 'Emerging Adulthood' on Dietary Patterns }}$}

This transitional time requires behavior adaptation to the new environment. The behaviors established during this transition could potentially initiate life-long weight struggles and the health problems associated with excess weight. ${ }^{46}$ The transition from high school to college is a critical period to understand in relation to dietary practices and health behaviors. ${ }^{40}$ Dietary practices established during college are likely to be maintained for life. This will impact 
the future health of the college student. ${ }^{29}$ 'Emerging adulthood' can be a time for high-risk health behaviors. ${ }^{16}$ The years of 'emerging adulthood' are an important time to focus on nutritionrelated issues because of the rising obesity rates during this time and the effects of obesity on long-term health. ${ }^{16}$ The transition from adolescence to young adulthood is becoming recognized as an important time for health promotion and disease prevention. ${ }^{17}$ Lasting health behavior patterns developed independently of parents may be developed during this time. ${ }^{17}$ 'Emerging adulthood' may be an important age for establishing long-term health behavior patterns although it is often overlooked. ${ }^{17}$ This is because of the increased risk for weight gain and diet quality decline. ${ }^{17}$ Many college students are living away from home for the first time. As they adopt new health behavior patterns on their own, there is potential to influence the establishment of important behavior patterns that can reduce the risk of some chronic disease. Universities therefore are a unique and appropriate setting to implement diet and lifestyle interventions. ${ }^{17}$

\section{$\underline{\text { Social Cognitive Theory and Self-Efficacy }}$}

The social cognitive theory, developed by Alberta Bandura in the 1970s, is a behaviorist view that claims individuals learn from observing and imitating other people's behavior, in addition to learning from external cues. ${ }^{54}$ In this type of learning, individuals are looking at the people around them and making decisions that affect their own learning. When this method is being used formally, such as during nutrition counseling, the registered dietitian must have the individual practice the skill to make sure the client is modeling the skill correctly. ${ }^{54}$ For example, the registered dietitian may have the client create daily menus to make sure the client understands principles of healthy meal planning. Self-efficacy is a situation-specific confidence on one's ability to successfully adopt a behavior or accomplish a task successfully without relapse. ${ }^{55}$ It is a crucial part of the social cognitive theory in predicting behavior change because 
it is the individual's perception about accomplishing the behavior change, not the individual's actual ability to do so, that determines how well that individual achieves and maintains these changes. ${ }^{54,56}$ Bandura believes that behavior changes do not originate from will power but from an individual's confidence in his or her ability to practice or achieve a specific behavior. ${ }^{57}$ Research indicates that health promotion programs based on the social cognitive theory can improve the participant's self-efficacy in making healthier food choices to improve overall diet quality. Poddar conducted a study through a personal health class where the intervention group participated in a 5-week online course. Those who participated in the course used selfregulatory strategies more effectively by the end of the study. This indicates that online intervention strategies can be used to improve the college student's self-efficacy about dietary practices. ${ }^{58}$ Franko et al. assessed fruit and vegetable intake based on the social cognitive theory and found motivation to change eating behaviors was improved and participants were more likely to increase their self-efficacy for dietary change. ${ }^{5}$ Strong investigated lifestyle behaviors of the college age population and discovered that healthful eating was not considered a high priority. Students claimed that the decline in dietary habits was relative to school, which suggests that college students may not have adequate self-regulatory skills needed for self-efficacy and positive dietary behavior change. ${ }^{10}$ Another study assessed the self-regulation strategies of goal setting and self-monitoring to enhance dietary fiber intake self-efficacy. Goal setting was significant in improving dietary fiber self-efficacy. ${ }^{59}$ 


\section{Nutrition Intervention Programs on University Campuses}

\section{Traditional Nutrition Intervention Programs}

In the past, the most successful programs for diet modification have included personal contact with a registered dietitian or other health care provider. However, this method may not fit into the busy and unpredictable schedule of college students. ${ }^{29}$ Some institutions have implemented college nutrition courses in order to combat rising obesity rates of college students. One study found that this approach only increased the student's nutrition knowledge and did not change the actual dietary intake. $^{29}$

A nutrition course to help disease prevention and increase the consumption of whole grains showed that an interactive introductory nutrition class can be effective in increasing whole-grain intake by college students. ${ }^{60}$ The study suggests that an introductory nutrition course is cost effective for institutions to provide. ${ }^{60}$ Matvienko implied that a nutrition science course focusing on energy metabolism could help college students prevent weight gain because students increased their nutrition knowledge and maintained their body weight. ${ }^{24}$ However, the results indicated that educational intervention was most effective for the population at risk for weight gain, as opposed to those not at risk. ${ }^{24}$ Another researcher reported that a class-based nutrition intervention can help meet the fruit and vegetable daily requirements, although it should be noted that nutrition knowledge does not necessarily predict dietary change. ${ }^{29}$

\section{$\underline{\text { Online Nutrition Intervention Programs }}$}

Technology increasingly shapes how education is delivered and learning is presented. ${ }^{61}$ Students who perceive online learning as an acquirable skill had positive learning outcomes, while students who perceived that online learning was an unattainable skill had less success with online learning and lower efficacy levels. This indicates that it is not the actual technology itself 
that promotes or hinders learning — rather it is the student's perception of technology as a method for learning. ${ }^{61}$ Online research and learning has more cost savings and convenience-especially those using the programs already in existence at their institutions such as WebCT. ${ }^{62}$ Many universities require incoming freshmen to take an internet-based alcohol abuse prevention education program. ${ }^{63}$ In one study comparing the effectiveness of internet intervention with a face-to-face intervention, no difference was seen between the 2 interventions in terms of effectiveness. Therefore, online programs are helpful in preventing harmful behaviors for incoming college freshmen. ${ }^{63}$

An advantage of online educational programs and research is the ability to connect with individuals who are unwilling to participate in person due to the sensitive nature of the program. ${ }^{64}$ Online research may be better for qualitative health-related topics where the participants lack confidence to participate in face-to-face research methods. ${ }^{64}$ Gow et al. conducted a study on personalized weight gain and caloric intake that found that college students best responded to a combination of online education techniques including participant monitoring and feedback. Programs for weight gain prevention of college students need to include multiple components and be highly structured to be successful. ${ }^{65}$ Franko conducted a study through MyStudentBody.com-Nutrition (MSB-N) that showed that this web site could be effectively used to increase college students' fruit and vegetable consumption, increase positive changes in motivation to change dietary behaviors, and increase nutrition knowledge. ${ }^{5}$ Knowing that an online nutrition program can increase motivation to change has significant implications for the type of nutrition education provided to college students. ${ }^{66}$ The MyStudentBody.com-Nutrition program is an effective internet-based tool to promote changes in knowledge, attitudes, and 
behaviors of college students. This type of program can be used on many university campuses to increase healthy eating among college students. ${ }^{66}$

\section{Alternative Nutrition Intervention Programs}

Nutrition education and weight gain prevention programs can be delivered through online programs outside of the traditional internet portal associated with academic institutions. Social networks can be used to alter social norms related to obesity and may have effects on weight loss. ${ }^{67}$ With the integration of text messaging and Facebook into students' daily lives, there is now endless ability to deliver nutrition information through mediums that are frequently used. This is a low-cost and convenient platform for universities to use. ${ }^{68}$ Facebook and other social media platforms are ideal for providing weight loss information and changing the perception of weight behaviors on a large and cost-effective scale. ${ }^{69}$ Napolitano used Facebook to promote behavior change and weight loss. When combined with text messaging to disseminate encouragement and reminders, this intervention was found effective. Facebook interventions alone may not be enough to promote weight change. ${ }^{68}$

In A Call to Action to Prevent and Decrease Overweight and Obesity, an important setting to address the obesity epidemic in the United States is schools. ${ }^{6}$ Healthy Campus 2010 provides the national health objective of focusing on nutrition education in colleges and universities by increasing the number of college students who receive nutrition education from

their university directly. ${ }^{70}$ Universities need to take an active role in implementing and assessing health promotion programs to combat weight-related issues. ${ }^{45}$ Knowing the changes in the college student's eating behavior allows institutions to promote interventions that combat these negative behaviors. ${ }^{25}$ 
One university incorporated a nutrition workshop during summer orientation for incoming freshmen to attend. The workshop provided information about the skills students would need to make healthy choices in the buffet style campus dining facilities. The goal of this initiative is to increase student's ability and self-efficacy for becoming or remaining healthy during the transition from high school to college. ${ }^{22}$ Another institution used a cooking and nutrition television show, ‘Good Grubbin’, to address the lack of skills needed for meal planning and preparation among the college population. Those who watched the program regularly showed a change in knowledge and dietary behaviors. ${ }^{71}$ Newsletters disseminated in conjunction with a general nutrition course also proved to be effective in increasing college student's fruit and vegetable intake. ${ }^{29}$

\section{Call to Action}

It is important to develop programs to prevent weight gain for college students as they leave home and enter the college environment. ${ }^{65}$ Because obesity rates are rising in the adult population, the college student population has great potential for weight gain prevention interventions. ${ }^{25}$ Although research sheds light on many aspects of weight gain during the college years, relationships between eating and exercise behaviors and college student weight gain remain unclear. ${ }^{46}$ There appears to be little improvement in college students’ weight-related behaviors. ${ }^{50}$ Therefore, nutrition promotion among college students is an important area for future research. $^{16}$

Recent findings give direction about future nutrition intervention programs and research. Nutrition education programs will be more successful when they address environmental barriers and are combined with other health-promotion interventions. ${ }^{72}$ For college students, weight management interventions need to focus on the benefits of consuming a healthy diet that is 
relevant and important to this population. ${ }^{14}$ Interventions that include education about healthy eating, in addition to attitude assessment and personality evaluation, are more likely to be effective than education about weight reduction alone in overweight populations. ${ }^{73}$ Weightreduction interventions must also be aimed at behavior modification to be effective. ${ }^{73}$

Nutrition and exercise science educators are key in developing and implementing effective interventions to prevent the onset of obesity. ${ }^{14}$ These professional educators can be found on college campuses. The university's role in enhancing health awareness through dietary and exercise interventions is essential—so much so that these programs should be incorporated into the undergraduate level curriculum. ${ }^{4}$ The college student requires nutrition professionals to convey nutrition information differently from the adult population. ${ }^{74}$ Nutrition educators need to focus on flavor and appearance of food in terms of eating out, healthful eating on the run, habitual intakes of nutritious foods, and altering habitual foods so they are more nutrient dense. ${ }^{74}$ Interventions need to focus on the student's dietary self-regulation skills during the transition to college — this could be accomplished through a freshman program. ${ }^{15}$ Students, faculty, and staff of a university can participate in making changes within the university environment. ${ }^{14}$ 


\section{CHAPTER 3}

\section{METHODS}

\section{$\underline{\text { Program Description }}$}

BUCS: Live Well, a health and wellness program, was conducted for East Tennessee State University (ETSU) students. BUCS: Live Well was designed to serve as a pilot study in hopes of developing a campus-wide program for ETSU students. Recruitment of participants occurred through e-mails, flyers in academic buildings and residence halls, a booth in the student center, and advertising in various classes on campus.

The BUCS: Live Well program began on September $12^{\text {th }}$, 2011. Students came to Hutcheson Hall (as advertised) at designated times during the week to finalize registration and begin the program. The program was designed to last 12 weeks, with 10 weeks of data collection. The first and last weeks were designed for the initial and final assessment of the participants. Participants were randomly assigned to 1 of 2 groups: the control group (only weekly email newsletters given) and the intervention group (nutrition education videos and weekly newsletters given). During the initial assessment, participants signed the informed consent documents and completed a preevaluation questionnaire that took approximately 15 to 20 minutes to complete (Appendix A, Appendix B). This questionnaire assessed dietary habits, physical activity habits, and self-efficacy of health behaviors.

Height, waist circumference, weight, and body fat percentage were the anthropometrics collected on each participant. Height was measured to the nearest 0.25 inch with a stadiometer with participants removing their shoes. Participants were asked to remove their jackets and extra items before stepping on the scale for weight measurement using a HealthO Meter ${ }^{\circledR}$ Weight Tracking Scale and measured to the nearest one-tenth of a pound. Waist circumference was 
determined by using a nonstretch measuring tape with measurements to the nearest 0.01 centimeters. The BMI of each participant was calculated from the patient's height and weight after the initial assessment using the following Center for Disease Control formula: BMI = weight $(\mathrm{kg}) /$ height $\left(\mathrm{m}^{2}\right) .^{75}$ Body fat percentage was assessed using Omron ${ }^{\circledR}$ Fat Loss Monitor. Participants from both groups received pedometers and instructions on how to record their daily number of steps and exercise. Activity records were turned in each week.

Participants in both groups received weekly newsletters through their preferred email account that provided nutrition and exercise information (Table 1). The intervention group received additional nutrition education through videos disseminated through Goldlink, ETSU's online academic portal that all ETSU students have access to. The videos were research-based educational sessions with PowerPoint slides and audio of the presentation lasting approximately 10-20 minutes in length. Table 1 lists the newsletter and video topics. The educational videos were offered each week for the duration of the program. Students could access these videos at their convenience during the 12-week program.

Table 1 BUCS: Live Well Newsletter and Video Topics

\begin{tabular}{|l|l|l|}
\hline Week & Newsletter Topic & Video Topic \\
\hline Week 1 & Planning and Preparation & What is Eating Healthy and How Do You Do it? \\
\hline Week 2 & Weigh in on Diets & Get Moving \\
\hline Week 3 & Cooking Tips to Trim Fat & Show Me the Weigh! \\
\hline Week 4 & Snack Attacks & What's Your Eating Style? \\
\hline Week 5 & Increase Your Fiber & Sticker Shock \\
\hline Week 6 & Slow Down & You Call That a Serving? \\
\hline Week 7 & Shake the Salt Habit & What's in Your Grocery Chart? \\
\hline Week 8 & Healthy Eating Out & Eating Out Survival Guide \\
\hline Week 9 & A Salad Makeover & $\begin{array}{l}\text { The Good, Bad, and Ugly of Dieting: What Really } \\
\text { Works }\end{array}$ \\
\hline Week 10 & Cut Trans-Fats & What is on Your Plate? \\
\hline Week 11 & Have Your 5-9 Today? & Preventing Chronic Diseases \\
\hline Week 12 & n/a & $\begin{array}{l}\text { Do I Really Need a Vitamin, Mineral, or } \\
\text { Supplement? }\end{array}$ \\
\hline
\end{tabular}


During week 12 of BUCS: Live Well participants returned to Hutcheson Hall to complete the final questionnaire (Appendix C, Appendix D) and provide anthropometrics. Height was not measured, but weight, waist circumference, and body fat percentage were assessed using the same methods described for the initial assessment. Upon completion of the program, participants who met all the completion requirements received 25 dollars as an incentive for completing the program.

\section{Survey Design and Data Collection}

Data for BUCS: Live Well were collected through the preevaluation and postevaluation questionnaires of the control and intervention groups. The physical activity records reporting the number of steps each participant took in a day also provided data. The postevaluation asked many of the same questions to assess what changes occurred throughout the program. In order to assume content and construct validity, the evaluations were initially completed by ETSU clinical nutrition graduate students and revisions were made based upon their feedback.

\section{Study Sample}

The study subjects included males and females that met the following inclusion criteria: 1) 18 years or older; 2) ETSU student; 3) must be able to listen to weekly podcasts. The exclusion criteria for the participants were: 1) ETSU faculty or staff; 2) not able to speak or understand English; and 3) not an enrolled ETSU student; 4) currently participating in a weight management program; 5) physical or dietary limitations; and 6) presence of an underlying condition affecting weight status. BUCS: Live Well was a voluntary program that students chose to participate in. The study sample included those who participated in the 12-week program and met all of the requirements for completion. 


\section{$\underline{\text { Variable Selection }}$}

Analysis variables of the preevaluation and postevaluation included demographics, BMI, waist circumference, body fat percentage, residential status, self-efficacy, and health perceptions. Specific nutrition variables include intakes of specific foods from the food frequency questionnaire and self-reported intakes of fruits and vegetables. Analyses of the program’s success and the student's perception of the program were included in the post-evaluation questionnaire.

All heights were converted to meters (m) and all weights were converted to kilograms (kg) for statistical analysis. BMI was calculated during the preevaluation and postevaluation weight assessments using Quetelet's index of weight $(\mathrm{kg}) /$ height $(\mathrm{m})^{2} \cdot{ }^{75}$ It is important to note that the correlation between BMI and body fatness is less accurate in individuals with an increased percentage of fat-free mass, such as athletes. ${ }^{76}$ There are limitations with all BMI equations, but Quetelet's index is the most widely used standard in determining BMI. ${ }^{77}$ It is

recommended for use in all age groups and has a high correlation with adiposity. ${ }^{78}$

\section{$\underline{\text { Research Questions }}$}

The following research questions were explored using data collected from the preevaluation and postevaluation questionnaires:

1. How confident are students that they can incorporate positive dietary changes before and after BUCS: Live Well?

2. Will students report an increase in positive dietary habits after completing BUCS: Live Well?

3. Do weight status, residence, and health perceptions correlate with positive or negative dietary behaviors? 


\section{Institutional Review Board Approval}

BUCS: Live Well received Institutional Review Board (IRB) approval through the ETSU Office of Research and Sponsored Programs on August 11, 2011, to implement BUCS: Live Well the fall semester of 2011.

\section{$\underline{\text { Data Analysis }}$}

The Statistical Package for Social Sciences (SPSS) version 19.0 was used for all data analyses. Descriptive statistics were reported for demographic information and self-reported use of pedometers, number of fruit and vegetable servings per day, and perceived expectations of the BUCS: Live Well program. Independent t- tests were used to determine means and standard deviation (SD) of the BMI of individuals completing and not completing BUCS: Live Well. Paired samples t-tests were used to determine means and SD for number of fruit and vegetable servings per day, prior to beginning BUCS: Live Well and after completion of BUCS: Live Well. 


\section{CHAPTER 4}

\section{RESULTS}

The BUCS: Live Well program initially enrolled 64 participants and 57.8\% completed the program $(n=37)$. Of those who completed the program, 51.4\% $(n=19)$ were in the intervention group and $48.6 \%(n=18)$ were in the control group. Of the final participants in both groups, $5.4 \%$ were male and $94.6 \%$ were female. The age with the most representation from the final participation group was 18-24 years old (81.1\%), which was the age population the program planned to reach. The classifications of the final participants were $13.6 \%$ freshman, $10.8 \%$ sophomores, $21.6 \%$ juniors, $48.6 \%$ seniors, and $5.4 \%$ graduate students. The majority of the final participants (94.6\%) reported being white. Additionally, $75.7 \%$ of the final participants lived off campus while $24.3 \%$ lived on campus. When asked about employment, $70.3 \%$ of the participants were employed in some capacity. Areas of study among the intervention participants completing the program ( $\mathrm{n}=19)$ included: biology, clinical psychology, counseling, dental hygiene, exercise science, human services, microbiology, and nutrition. Nutrition was the major studied by the highest number of participants (47.1\%); dental hygiene was studied by the second highest number of participants (15.9\%). Additional demographics of the initial and final participants are reported in Table 2. 
Table 2 Demographics of Participants of BUCS: Live Well Program

\begin{tabular}{|l|c|c|}
\hline \multicolumn{1}{|c|}{ Variables } & $\begin{array}{c}\text { Initial Participants (\%) } \\
\mathrm{n}=64\end{array}$ & $\begin{array}{c}\text { Final Participants (\%) } \\
\mathrm{n}=37\end{array}$ \\
\hline Gender & 12.5 & 5.4 \\
Male & 87.5 & 94.6 \\
Female & & \\
\hline Age & 82.8 & 81.1 \\
18-24 years old & 9.4 & 10.8 \\
25-29 years old & 6.2 & 5.4 \\
30-39 years old & 0 & 0 \\
40-49 years old & 1.6 & 2.7 \\
50 and older & & \\
Race & 98.4 & 94.6 \\
White & 0 & 0 \\
Black & 0 & 2.7 \\
Hispanic & 1.6 & 2.7 \\
Other & & \\
\hline Classification & 20.3 & 13.6 \\
Freshman & 9.4 & 10.8 \\
Sophomore & 25.0 & 21.6 \\
Junior & 40.6 & 48.6 \\
Senior & 4.7 & 5.4 \\
Graduate Student & & \\
\hline Residence & 26.6 & 24.3 \\
On Campus & 73.4 & 75.7 \\
Off Campus & 60.9 & 29.7 \\
\hline Employment & 39.1 & \\
Yes & & \\
No & & \\
\hline
\end{tabular}

The BMI of the final participants was calculated from $\mathrm{kg} / \mathrm{m}^{2}$ at the beginning and end of the program. Initially, 23 participants were classified as normal weight based on BMI, while 22 held this classification at the end of the program. The initial BMI classifications of the final participants were $2.7 \%$ underweight, $62.6 \%$ normal weight, $29.7 \%$ overweight, $2.7 \%$ obese class I and $2.7 \%$ obese class II. BMI classifications at the conclusion of the program were $2.7 \%$ underweight, $59.5 \%$ normal weight, $32.4 \%$ overweight, $2.7 \%$ obese class I, and $2.7 \%$ obese class II. The majority of participants (62.2\%) were within normal body weight, according to BMI, at the onset of the program but that percentage decreased at the conclusion of the program, with 
one person actually gaining weight and being classified as overweight. Two individuals increased in weight circumference from the 20.0 to 29.9 inch category to the 30.0 to 39.9 inch category. A decrease in body fat percentage was seen in the individuals with the highest initial body fat percentage (40.0 to 49.9 inches) from $5.4 \%$ to $0 \%$. Table 3 depicts additional anthropometric information related to BMI, weight, waist circumference, and body fat percentage.

Table 3 BMI, Weight, Waist Circumference, and Body Fat Percentage Measurements of BUCS: Live Well Participants $(\mathrm{n}=37)$

\begin{tabular}{|c|c|c|c|c|}
\hline Variable & $\begin{array}{c}\text { Initial } \\
\text { Frequency } \\
\text { (n) }\end{array}$ & $\begin{array}{c}\text { Initial } \\
\text { Percentage } \\
(\%)\end{array}$ & $\begin{array}{c}\text { Final } \\
\text { Frequency } \\
\text { (n) }\end{array}$ & $\begin{array}{c}\text { Final } \\
\text { Percentage } \\
(\%)\end{array}$ \\
\hline \multicolumn{5}{|l|}{ BMI Classification $^{\mathrm{a}}$} \\
\hline Underweight (18.4 or less) & 1 & 2.7 & 1 & 2.7 \\
\hline Normal Weight (18.5-24.9) & 23 & 62.2 & 22 & 59.5 \\
\hline Overweight (25.0-29.9) & 11 & 29.7 & 12 & 32.4 \\
\hline Obese-Class I (30.0-34.9) & 1 & 2.7 & 1 & 2.7 \\
\hline Obese-Class II (35.0 or greater) & 1 & 2.7 & 1 & 2.7 \\
\hline \multicolumn{5}{|l|}{ Weight (kg) } \\
\hline $40.00-49.99$ & 3 & 8.1 & 2 & 5.4 \\
\hline 50.00-59.99 & 15 & 40.5 & 17 & 46.0 \\
\hline 60.00-69.99 & 10 & 27.1 & 7 & 18.9 \\
\hline 70.00-79.99 & 4 & 10.8 & 7 & 18.9 \\
\hline 80.00-89.99 & 3 & 8.1 & 2 & 5.4 \\
\hline 90.00-99.99 & 1 & 2.7 & 1 & 2.7 \\
\hline 100.00 and greater & 1 & 2.7 & 1 & 2.7 \\
\hline \multicolumn{5}{|l|}{ Waist Circumference (inches) } \\
\hline 20.0-29.9 & 18 & 48.6 & 16 & 43.2 \\
\hline $30.0-39.9$ & 18 & 48.6 & 20 & 54.1 \\
\hline $40.0-49.9$ & 0 & 0 & 0 & 0 \\
\hline 50 and greater & 1 & 2.8 & 1 & 2.7 \\
\hline \multicolumn{5}{|l|}{ Body Fat (percentage) } \\
\hline 9.99 and less & 0 & 0 & 0 & 0 \\
\hline 10.0-19.9 & 11 & 29.7 & 10 & 27.0 \\
\hline $20.0-29.9$ & 18 & 48.6 & 19 & 51.4 \\
\hline $30.0-39.9$ & 6 & 16.3 & 8 & 21.6 \\
\hline $40.0-49.9$ & 2 & 5.4 & 0 & 0 \\
\hline
\end{tabular}


No significant difference was found between the initial BMIs of those starting BUCS: Live Well and those completing the program $(P=0.209)$. The BMI range was wider for those completing the program (16.7 to $48.6 \mathrm{~kg} / \mathrm{m}^{2}$ ) than those not completing the program (18.1 to 33.5 $\mathrm{kg} / \mathrm{m}^{2}$ ) although the mean BMI was the similar with $24.5 \mathrm{~kg} / \mathrm{m}^{2}$ for those not completing the program and $24.2 \mathrm{~kg} / \mathrm{m}^{2}$ for those completing the program (Table 4).

Table 4 BMI of Initial and Final BUCS: Live Well Participants

\begin{tabular}{|c|c|c|c|c|c|}
\hline & $\mathrm{n}$ & Mean BMI $\left(\mathrm{kg} / \mathrm{m}^{2}\right)$ & $\begin{array}{l}\text { Minimum } \\
\text { BMI }\left(\mathrm{kg} / \mathrm{m}^{2}\right)\end{array}$ & $\begin{array}{c}\text { Maximum } \\
\text { BMI }\left(\mathrm{kg} / \mathrm{m}^{2}\right)\end{array}$ & $P$ value ${ }^{b}$ \\
\hline $\begin{array}{l}\mathrm{BMI}^{\mathrm{a}} \text { Not } \\
\text { Completing BUCS: } \\
\text { Live Well }\end{array}$ & 27 & $24.5 \pm 3.89$ & 18.1 & 33.5 & \multirow[t]{2}{*}{0.209} \\
\hline $\begin{array}{l}\text { BMI }^{\mathrm{a}} \text { Completing } \\
\text { BUCS: Live Well }\end{array}$ & 37 & $24.2 \pm 5.34$ & 16.7 & 48.6 & \\
\hline
\end{tabular}

\section{Research Question 1:}

How confident are students that they can incorporate positive dietary changes before and after BUCS: Live Well?

From the participants who completed BUCS: Live Well, 37.8\% initially said they were very satisfied with their mood/emotion, which increased to $40.5 \%$ after the program. Those very satisfied in their confidence/self assurance at the beginning of the program were $29.7 \%$, which increased to $40.5 \%$ after the program. On the contrary, an individual reported being very dissatisfied in his or her confidence/self-assurance after the program. Out of the final participants, $21.6 \%$ said they started the program feeling somewhat dissatisfied in their energy and feeling healthy, which decreased to $13.5 \%$ after the program. The number of participants reporting that they were somewhat satisfied or very satisfied in their energy and feeling healthy before the program increased from $67.6 \%$ to $81.1 \%$. Fewer participants felt very satisfied and 
more participants felt somewhat dissatisfied with their appearance after the program. Self-

perceptions related to satisfaction in various aspects of daily life are reported in Table 5.

Table 5 Self-Perception of Initial and Final Participants of BUCS: Live Well ( $\mathrm{n}=37)$

\begin{tabular}{|l|c|c|c|c|}
\hline \multicolumn{1}{|c|}{$\begin{array}{c}\text { Satisfaction Ratings of Various } \\
\text { Aspects in Daily Life }\end{array}$} & $\begin{array}{c}\text { Initial } \\
\text { Frequency } \\
\text { (n) }\end{array}$ & $\begin{array}{c}\text { Initial } \\
\text { Percentage } \\
(\%)\end{array}$ & $\begin{array}{c}\text { Final } \\
\text { Frequency } \\
\text { (n) }\end{array}$ & $\begin{array}{c}\text { Final } \\
\text { Percentage } \\
(\%)\end{array}$ \\
\hline Mood/Emotion & 1 & 2.7 & 1 & 2.7 \\
$\quad$ Very Dissatisfied & 3 & 8.1 & 6 & 16.2 \\
Somewhat Dissatisfied & 6 & 16.2 & 3 & 8.1 \\
Neutral & 13 & 35.1 & 12 & 32.4 \\
Somewhat Satisfied & 14 & 37.8 & 15 & 40.5 \\
Very Satisfied & & & & \\
\hline Confidence/Self-Assurance & 0 & 0 & 1 & 2.7 \\
Very Dissatisfied & 2 & 5.4 & 2 & 5.4 \\
Somewhat Dissatisfied & 5 & 13.5 & 5 & 13.5 \\
Neutral & 19 & 51.4 & 14 & 37.8 \\
Somewhat Satisfied & 11 & 29.7 & 15 & 40.5 \\
$\quad$ Very Satisfied & 1 & & & \\
\hline Energy and Feeling Healthy & 8 & 2.7 & 0 & 0 \\
Very Dissatisfied & 3 & 8.1 & 5 & 13.5 \\
Somewhat Dissatisfied & 15 & 40.5 & 17 & 5.4 \\
Neutral & 10 & 27.1 & 13 & 46.0 \\
Somewhat Satisfied & & & & 35.1 \\
Very Satisfied & 1 & 2.7 & 0 & 0 \\
\hline Your Appearance & 4 & 10.8 & 6 & 16.2 \\
Very Dissatisfied & 7 & 19.0 & 5 & 13.5 \\
Somewhat Dissatisfied & 15 & 40.5 & 19 & 51.4 \\
Neutral & 10 & 27.0 & 7 & 18.9 \\
Somewhat Satisfied & & & & \\
Very Satisfied & & &
\end{tabular}

Among the participants of both groups who completed BUCS: Live Well, 35.1\% initially stated they agreed with the statement "I am satisfied with my weight.” This percentage increased to $37.8 \%$ after the completion of the program. Overall, $54.0 \%$ of the participants initially stated that they strongly agreed or agreed with the statement "I am satisfied with my weight" which decreased to $51.4 \%$ after the program. The program helped improve weight satisfaction to some extent. No significant changes were found in the participant's description of weight status or if 
the participant was currently trying to lose weight before and after the program. Before the program, $10.9 \%$ of the participants said it is very easy to eat a little less each day, which increased to $16.2 \%$ after the program although the number who reported that it was somewhat difficult to eat a little less each day increased. When asked about consistently limiting daily calorie intake to maintain current weight or to lose weight, $21.6 \%$ initially stated they have been doing this for 6 months or longer, which increased to 35.1\%. At the beginning, $19.0 \%$ stated that they were limiting caloric intake for less than 6 months, which decreased to $16.2 \%$. When asked about current caloric intake, $21.6 \%$ indicated they were not limiting caloric intake, but intended to in the next 30 days, which decreased to $10.9 \%$. Initially, $16.2 \%$ said they were not limiting caloric intake but they intended to in the next 6 months. This percentage increased to $24.3 \%$ after the study. The percentage of those who were not limiting caloric intake and did not intend to in the next 6 months decreased from $21.6 \%$ to 13.5\%. The program either helped initiate limiting caloric intake or supported those participants already limiting caloric intake for weight loss or weight maintenance. There was an increase in the percentage of participants who stated that eating healthy was extremely important from $40.5 \%$ to $48.7 \%$, although the number of participants reporting that eating healthy daily was either extremely not important or not important increased from $2.7 \%$ to $8.1 \%$. Table 6 summarizes the participant's weight perceptions as determined by their survey responses. 
Table 6 Weight Perception Survey Responses of BUCS: Live Well Participants (n=37)

\begin{tabular}{|c|c|c|c|c|}
\hline Question & $\begin{array}{c}\text { Initial } \\
\text { Frequency } \\
\text { (n) }\end{array}$ & $\begin{array}{c}\text { Initial } \\
\text { Percentage } \\
(\%) \\
\end{array}$ & $\begin{array}{c}\text { Final } \\
\text { Frequency } \\
\text { (n) }\end{array}$ & $\begin{array}{c}\text { Final } \\
\text { Percentage } \\
(\%)\end{array}$ \\
\hline \multicolumn{5}{|l|}{ I am Satisfied with My Weight } \\
\hline Strongly Agree or Agree & 20 & 54.0 & 19 & 51.4 \\
\hline Neutral & 4 & 10.9 & 10 & 27.0 \\
\hline Disagree or Strongly Disagree & 13 & 35.1 & 8 & 21.6 \\
\hline \multicolumn{5}{|l|}{ How Would You Describe Your Weight? } \\
\hline Very Underweight & 0 & 0 & 0 & 0 \\
\hline Slightly Underweight & 3 & 8.1 & 2 & 5.4 \\
\hline About the Right Weight & 20 & 54.1 & 20 & 54.1 \\
\hline Slightly Overweight & 13 & 35.1 & 14 & 37.8 \\
\hline Very Overweight & 1 & 2.7 & 1 & 2.7 \\
\hline \multicolumn{5}{|l|}{ Are You Currently Trying to Lose Weight? } \\
\hline Yes & 13 & 35.1 & 13 & 35.1 \\
\hline No & 24 & 64.9 & 24 & 64.9 \\
\hline \multicolumn{5}{|l|}{ How Difficult is it for You to Eat a Little } \\
\hline \multicolumn{5}{|l|}{ Less Each Day? } \\
\hline No answer & 0 & 0 & 1 & 2.7 \\
\hline Very Difficult & 2 & 5.4 & 2 & 5.4 \\
\hline Somewhat Difficult & 8 & 21.6 & 12 & 32.4 \\
\hline Neither Difficult or Easy & 14 & 37.8 & 7 & 19.0 \\
\hline Somewhat Easy & 9 & 24.3 & 9 & 24.3 \\
\hline Very Easy & 4 & 10.9 & 6 & 16.2 \\
\hline \multicolumn{5}{|l|}{ Do you Consistently Limit your Daily } \\
\hline \multicolumn{5}{|l|}{ Calorie Intake to Maintain your Current } \\
\hline \multicolumn{5}{|l|}{ Weight or to Lose Weight? } \\
\hline Yes, I have been for 6 months or longer & 8 & 21.6 & 13 & 35.1 \\
\hline Yes, I have but for less than 6 months & 7 & 19.0 & 6 & 16.2 \\
\hline No, but I intend to in the next 30 days & 8 & 21.6 & 4 & 10.9 \\
\hline No, but I intend to in the next 6 months & 6 & 16.2 & 9 & 24.3 \\
\hline $\begin{array}{l}\text { No, and I do not intent to in the next } 6 \\
\text { months }\end{array}$ & 8 & 21.6 & 5 & 13.5 \\
\hline \multicolumn{5}{|l|}{ How Important is it to You to "Eat Healthy" } \\
\hline \multicolumn{5}{|l|}{ Daily } \\
\hline Extremely not Important & 1 & 2.7 & 2 & 5.4 \\
\hline Not Important & 0 & 0 & 1 & 2.7 \\
\hline Neither Important nor Unimportant & 2 & 5.4 & 1 & 2.7 \\
\hline Somewhat Important & 19 & 51.4 & 15 & 40.5 \\
\hline Extremely Important & 15 & 40.5 & 18 & 48.7 \\
\hline
\end{tabular}

In assessing the diet habits of the participants from both groups ( $\mathrm{n}=37), 27.0 \%$ initially disagreed with the statement "I am too busy to eat healthy foods", whereas $45.9 \%$ of the 
participants disagreed with the statement after the program. This shows improvement in the participant's attitude toward consuming healthy foods while maintaining a busy schedule. There were no significant changes in the participants' perception about healthy food costing too much. Also, $27.0 \%$ initially indicated that they disagreed with the statement "eating healthy takes too much time” whereas, after the program, $40.5 \%$ disagreed with the statement showing that more students felt like eating healthy did not take too much time after the program. Diet habit survey responses are summarized in Table 7.

Table 7 Diet Habit Survey Responses of BUCS: Live Well Participants ( $\mathrm{n}=37$ )

\begin{tabular}{|c|c|c|c|c|}
\hline Question & $\begin{array}{c}\text { Initial } \\
\text { Frequency } \\
\text { (n) }\end{array}$ & $\begin{array}{c}\text { Initial } \\
\text { Percentage } \\
(\%)\end{array}$ & $\begin{array}{c}\text { Final } \\
\text { Frequency } \\
\text { (n) }\end{array}$ & $\begin{array}{c}\text { Final } \\
\text { Percentage } \\
(\%)\end{array}$ \\
\hline \multicolumn{5}{|l|}{ I am too Busy to Eat Healthy Foods } \\
\hline Strongly Agree & 2 & 5.4 & 1 & 2.7 \\
\hline Agree & 3 & 8.1 & 4 & 10.8 \\
\hline Neutral & 4 & 10.8 & 5 & 13.5 \\
\hline Disagree & 10 & 27.0 & 17 & 45.9 \\
\hline Strongly Disagree & 18 & 48.6 & 10 & 27.0 \\
\hline \multicolumn{5}{|l|}{ Healthy Foods Cost too Much } \\
\hline Strongly Agree & 5 & 13.5 & 3 & 8.1 \\
\hline Agree & 10 & 27.0 & 13 & 35.1 \\
\hline Neutral & 6 & 16.2 & 5 & 13.5 \\
\hline Disagree & 8 & 21.6 & 10 & 27.0 \\
\hline Strongly Disagree & 8 & 21.6 & 6 & 16.2 \\
\hline \multicolumn{5}{|l|}{ Eating Healthy Just Takes Too Much } \\
\hline Time & & & & \\
\hline Strongly Agree & 2 & 5.4 & 0 & 0 \\
\hline Agree & 5 & 13.5 & 3 & 8.1 \\
\hline Neutral & 6 & 16.2 & 9 & 24.3 \\
\hline Disagree & 10 & 27.0 & 15 & 40.5 \\
\hline Strongly Disagree & 14 & 37.8 & 10 & 27.0 \\
\hline
\end{tabular}

Paired Samples t-tests assessed the participant’s confidence to make specific dietary choices before and after the BUCS: Live Well program. Table 8 and Table 9 show the change in confidence levels regarding fruit servings, vegetable servings, regular soda intake, fast food intake, limiting portion sizes, and breakfast consumption. There were some positive changes 
although these changes were not significant. The participants' confidence to eat at least 3 servings of vegetables a day and the confidence to eat breakfast on most dates improved in the control group. The control participants' confidence to eat at least 2 servings of fruit a day, confidence to limit fast food, and confidence to limit portion sizes slightly regressed after the program. The control group confidence to limit the amount of regular sodas consumed daily did not change. For the intervention participants, the confidence to eat at least 2 servings of fruit a day, eat at least 3 servings of vegetables a day, and to eat breakfast on most days improved, although there was no significance. The confidence to limit fast food frequency stayed the same while the confidence to limit sodas and limit portion sizes decreased slightly. Reported confidence improvement was assessed by the mean responses on the questionnaire with an answer of 1 being very confident, 2 being somewhat confident, 3 being neutral, 4 being somewhat confident, and 5 being not confident at all.

Table 8 Paired Samples t-tests Preevaluation and Postevaluation of Confidence Survey Questions of BUCS: Live Well Final Control Participants $(\mathrm{n}=18)^{\mathrm{a}}$

\begin{tabular}{|l|c|c|c|}
\hline \multicolumn{1}{|c|}{ Questions } & $\begin{array}{c}\text { Preevaluation } \\
\text { mean } \pm \text { SD }\end{array}$ & $\begin{array}{c}\text { Postevaluation } \\
\text { mean } \pm \text { SD }\end{array}$ & $P$ value $^{\mathrm{b}}$ \\
\hline $\begin{array}{l}\text { Confidence to eat at least } 2 \\
\text { servings of fruit a day }\end{array}$ & $1.28 \pm 0.83$ & $1.33 \pm 0.77$ & 0.805 \\
\hline $\begin{array}{l}\text { Confidence to eat at least 3 } \\
\text { servings of vegetables a day }\end{array}$ & $1.94 \pm 0.10$ & $1.89 \pm 1.02$ & 0.772 \\
\hline $\begin{array}{l}\text { Confidence to limit amount of } \\
\text { regular sodas consumed a day }\end{array}$ & $1.11 \pm 0.47$ & $1.11 \pm 0.47$ & ${\mathrm{n} / \mathrm{a}^{\mathrm{c}}}$ \\
\hline $\begin{array}{l}\text { Confidence to limit frequency } \\
\text { of eating at fast food restaurants }\end{array}$ & $1.33 \pm 0.49$ & $1.61 \pm 1.04$ & 0.135 \\
\hline $\begin{array}{l}\text { Confidence to limit portion } \\
\text { sizes of foods eaten }\end{array}$ & $1.67 \pm 0.84$ & $1.83 \pm 0.86$ & 0.269 \\
\hline $\begin{array}{l}\text { Confidence to eat breakfast on } \\
\text { most days }\end{array}$ & $1.39 \pm 0.61$ & $1.28 \pm 0.57$ & 0.495 \\
\hline $\begin{array}{l}\mathrm{a} 1=\text { Very Confident, 2=Somewhat } \\
\text { All Confident } \\
\text { b Significant at } \alpha<.05 \text { level } \\
\mathrm{c} \text { The correlation and t-test cannot be computed because the standard error of the difference is 0 }\end{array}$ \\
\hline
\end{tabular}


Table 9 Paired Samples t-tests Preevaluation and Postevaluation of Confidence Survey Questions of BUCS: Live Well Final Intervention Participants $(n=19)^{\mathrm{a}}$

\begin{tabular}{|l|c|c|c|}
\hline \multicolumn{1}{|c|}{ Questions } & $\begin{array}{c}\text { Preevaluation } \\
\text { mean } \pm \text { SD }\end{array}$ & $\begin{array}{c}\text { Postevaluation } \\
\text { mean } \pm \text { SD }\end{array}$ & $\begin{array}{l}P \\
\text { value }^{\mathrm{b}}\end{array}$ \\
\hline $\begin{array}{l}\text { Confidence to eat at least } 2 \\
\text { servings of fruit a day }\end{array}$ & $1.26 \pm 0.45$ & $1.21 \pm 0.54$ & 0.716 \\
\hline $\begin{array}{l}\text { Confidence to eat at least 3 } \\
\text { servings of vegetables a day }\end{array}$ & $1.58 \pm 0.77$ & $1.42 \pm 0.69$ & 0.482 \\
\hline $\begin{array}{l}\text { Confidence to limit amount of } \\
\text { regular sodas consumed a day }\end{array}$ & $1.00 \pm 0.00$ & $1.05 \pm 0.23$ & 0.331 \\
\hline $\begin{array}{l}\text { Confidence to limit frequency } \\
\text { of eating at fast food restaurants }\end{array}$ & $1.42 \pm 0.51$ & $1.42 \pm 0.77$ & 1.000 \\
\hline $\begin{array}{l}\text { Confidence to limit portion } \\
\text { sizes of foods eaten }\end{array}$ & $1.79 \pm 0.63$ & $2.05 \pm 1.18$ & 0.834 \\
\hline $\begin{array}{l}\text { Confidence to eat breakfast on } \\
\text { most days }\end{array}$ & $1.10 \pm 0.23$ & $1.05 \pm 0.05$ & 1.000 \\
\hline $\begin{array}{l}\text { a } 1=\text { Very Confident, 2=Somewhat Confident, 3=Neutral, 4=Somewhat not Confident, 5=Not at } \\
\begin{array}{l}\text { All Confident } \\
\text { b Significant at } \alpha<.05 \text { level }\end{array}\end{array}$ \\
\hline
\end{tabular}

\section{Research Question 2:}

Will students report an increase in positive dietary habits after completing BUCS: Live Well?

Participant intake of fruit, vegetables, salt, and fat determines the appropriateness of nutrient composition in dietary intake. Among all the participants who completed the program ( $n=37), 5.4 \%$ initially reported they ate 4 servings of fruit a day, which increased to $19.0 \%$ after the completion of the program. Initially, $10.9 \%$ of this group reported consuming 4 servings of vegetables each day, which increased to $27.0 \%$ after the program. Consumption of 4 servings of fruit and vegetables each day increased. A serving of fruit was defined in the survey as 1 whole fresh fruit, $1 / 2$ cup canned fruit, or $1 / 2$ cup fruit juice. A serving of vegetables was defined as $1 / 2$ cup cooked vegetables or 1 cup of raw vegetables. Those participants consuming 4 servings of fruits and vegetables would be close to meeting the recommended daily consumption; The United Stated Department of Agriculture recommends consuming 2 cups of fruit and $2 \frac{1}{2}$ cups of 
vegetables each day based on an adult 2000 calorie diet. ${ }^{79}$ There was a significant increase in the percentage of participants actively trying to avoid high salt foods from $59.5 \%$ to $75.7 \%$ after the program ( $\mathrm{p}=0.032$ ). According to the current Dietary Guidelines for Americans, sodium intake should be reduced to less than 2300 milligrams (mg) each day. ${ }^{80}$ Reducing sodium intake is in accordance with these national guidelines. The percentage of students actively trying to avoid high fat foods decreased slightly from $75.5 \%$ to $73 \%$ after the program.

When fruit, vegetable, salt, and fat intake were assessed among the intervention group participants alone, 5.3\% reported consuming 4 fruit servings a day, which increased to $26.3 \%$, after the completion of the program. The percentage of participants consuming 4 servings of vegetables each day increased from $10.5 \%$ to $13.5 \%$. There was also an increase in the percentage of participants actively trying to avoid high salt foods from $52.6 \%$ to $73.7 \%$. The percentage of participants actively trying to avoid high fat foods decreased from $73.7 \%$ to $68.4 \%$ after the program.

Control participants consuming 4 servings of fruits each day increased from 5.6\% before the program to $11.1 \%$ after the program. The percentage of those consuming 4 servings of vegetables each day increased from $11.1 \%$ to $27.8 \%$ after the program. After the completing the program, $77.8 \%$ of this group reported actively trying to avoid high salt foods, which is an increase from the initial $66.7 \%$. The percentage of students actively trying to avoid high fat foods did not change after completion of the program. Overall completion group nutrient intake information can be found in Table 10 . 
Table 10 Paired Samples t-test of Fruit, Vegetable, Salt, and Fat Intake of All BUCS: Live Well Participants that Completed the Program $(n=37)$

\begin{tabular}{|c|c|c|c|c|c|}
\hline Items & $\begin{array}{l}\text { Before } \\
\text { Program } \\
(\%)\end{array}$ & $\begin{array}{c}\text { After } \\
\text { program } \\
(\%)\end{array}$ & $\begin{array}{c}\text { Before } \\
\text { Program } \\
\text { Mean } \pm \text { SD }\end{array}$ & $\begin{array}{l}\text { After Program } \\
\text { Mean } \pm \text { SD }\end{array}$ & $P$ value $^{\mathrm{a}}$ \\
\hline $\begin{array}{l}\text { Number of Fruit Servings per } \\
\text { day } \\
0 \\
1 \\
2 \\
3 \\
4 \\
5 \\
6 \text { or more }\end{array}$ & $\begin{array}{c}2.7 \\
16.2 \\
35.2 \\
32.4 \\
5.4 \\
8.1 \\
0\end{array}$ & $\begin{array}{c}0 \\
21.6 \\
27.0 \\
29.7 \\
19.0 \\
2.7 \\
0\end{array}$ & $2.46 \pm 1.17$ & $2.54 \pm .12$ & 0.597 \\
\hline $\begin{array}{l}\text { Number of Vegetable } \\
\text { Servings per day } \\
0 \\
1 \\
2 \\
3 \\
4 \\
5 \\
6 \text { or more }\end{array}$ & $\begin{array}{c}5.4 \\
16.2 \\
29.7 \\
29.7 \\
10.9 \\
5.4 \\
2.7\end{array}$ & $\begin{array}{c}2.7 \\
19.0 \\
24.3 \\
21.6 \\
27.0 \\
2.7 \\
2.7\end{array}$ & $2.51 \pm 1.35$ & $2.70 \pm 1.35$ & 0.213 \\
\hline $\begin{array}{l}\text { Actively try to avoid high salt } \\
\text { foods } \\
\text { Yes } \\
\text { No }\end{array}$ & $\begin{array}{l}59.5 \\
40.5\end{array}$ & $\begin{array}{l}75.7 \\
24.3\end{array}$ & $1.41 \pm 0.50$ & $1.24 \pm 0.44$ & $0.032^{\mathrm{a}}$ \\
\hline $\begin{array}{l}\text { Actively try to avoid high } \\
\text { total fat foods } \\
\text { Yes } \\
\text { no }\end{array}$ & $\begin{array}{l}75.7 \\
24.3\end{array}$ & $\begin{array}{l}73.0 \\
27.0\end{array}$ & $1.24 \pm 0.44$ & $1.27 \pm 0.45$ & 0.711 \\
\hline
\end{tabular}

The preevaluations and postevaluations included a 19-item food frequency questionnaire designed to assess dietary intake of regular and diet sodas, sweetened and unsweetened tea, energy drinks or flavored waters, alcoholic drinks, fruit, green salad, french fries and/or fried potatoes, vegetables, potato chips, baked crackers and chips, white and whole grain breads and pasta, and sweets/other desserts. Appendix F shows the frequency and percentage of participants consuming these foods daily, 4-6 times a week, 1-3 times a week, 1 time a month, never, or not 
sure before and after the program for all participants, control participants, and intervention participants separately.

From this group of all participants (n=37), 48.6\% consumed fruit daily and 37.8\% consumed vegetables daily before the program. The number of reported daily fruit consumption decreased after the program while the number of reported daily vegetable consumption did not change significantly. Prior to beginning the program, 40.5\% consumed salad 1-3 times a week, which increased after the program, to $62.2 \%$ of the participants. The percentage of participants consuming whole grain breads daily increased from $24.3 \%$ to $29.7 \%$ after completion of the program. The percentage of participants consuming whole grain pasta daily also increased from $2.7 \%$ to $5.4 \%$. The daily consumption of sweets and other desserts decreased from $16.2 \%$ to $10.8 \%$ after the program.

The food frequency questionnaire of the intervention group indicates that the daily consumption of fruit decreased from $47.4 \%$ to $31.6 \%$ after the program. Initially $42.1 \%$ consumed green salad 1-3 times a week, and after the program 57.9\% reported they consumed green salad at this same frequency; however, the daily consumption decreased from $10.5 \%$ to $5.3 \%$. There was an increase in the percentage of participants who consume vegetables 1-3 times a week from $15.8 \%$ to $26.3 \%$. The daily consumption of vegetables also increased from $31.6 \%$ to 47.4\%. Daily consumption of whole grain breads increased from $26.3 \%$ to $42.1 \%$ after the program. Consumption daily of sweets and other desserts decreased from $21.1 \%$ to $5.3 \%$. Among the control group participants, $16.7 \%$ initially consumed fruit 1-3 times a week, and after the program $27.8 \%$ reported doing this. However, daily consumption of fruit decreased after the program from $50.5 \%$ to $44.4 \%$. Also, $38.9 \%$ reported consuming green salad $1-3$ times a week, which increased to $66.7 \%$ after the duration of the program even though the daily 
consumption decreased from $11.1 \%$ to $5.6 \%$. When assessing vegetable consumption, initially $16.7 \%$ of this group reported consuming vegetables 4-6 times a week. This percentage increased to $38.9 \%$ after completion of the program. Daily consumption of vegetables decreased from $44.4 \%$ to $27.8 \%$ after the program. The consumption of whole grain breads also decreased from $22.2 \%$ to $16.7 \%$ after the program although the daily consumption of whole grain pasta remained the same. The daily consumption of sweets and other desserts increased from $11.1 \%$ to $16.7 \%$. Research Question 3:

Do weight status, residence, and health perceptions correlate with positive or negative dietary behaviors?

Among the participants completing the program from both the intervention and control group ( $n=37$ ), several significant correlations were found. There is a significant correlation between weight satisfaction and actual BMI before and after the program $(r=0.522, p=.01$ and $\mathrm{r}=0.581 \mathrm{p}=.01$, respectively). Another significant correlation was found between weight satisfaction and body fat percentage before and after the program $(r=0.598, p=.01$ and $r=0.646$, $\mathrm{p}=.01$ respectively). The participants' description of his or her weight and the participant's actual BMI before and after the program was significantly correlated $(\mathrm{r}=0.739, \mathrm{p}=.01 \mathrm{and}$ $\mathrm{r}=0.768, \mathrm{p}=.01$ respectively). The participant's satisfaction with his or her weight and the description of current weight status (with the options of very underweight, underweight, normal weight, overweight, or very overweight) also has a significant correlation before and after the program ( $r=0.696, p=.01$ and $r=0.690, p=.01$ respectively). These correlations imply that the participants had an accurate self-perception of their satisfaction in and description of their weight status as it relates to health implications. The participants’ current weight loss attempts and actual BMI are significantly negatively correlated before and after completion of the program (r= 
$-.416, \mathrm{p}=.05$ and $\mathrm{r}=-0.476, \mathrm{p}=.01$ respectively). This implies that those attempting to lose weight are those with the higher BMI statuses. Vegetable intake and confidence to improve vegetable intake are also significantly negatively correlated before and after the program ( $\mathrm{r}=$ 0.447, $\mathrm{p}=.01$ and $\mathrm{r}=-0.506, \mathrm{p}=.01$ respectively). This means that confidence to improve vegetable intake is not associated with improved vegetable intake. These correlations and more are reported in Table 11.

Table 11 Correlations of Final BUCS: Live Well Participants (n=37)

\begin{tabular}{|c|c|c|}
\hline Variables & $\begin{array}{l}\text { Before } \\
\text { Program }(r)\end{array}$ & $\begin{array}{l}\text { After } \\
\text { Program }(r)\end{array}$ \\
\hline \multicolumn{3}{|l|}{ Residence (On-campus or Off-campus) } \\
\hline Body Mass Index & -0.029 & -0.029 \\
\hline Fruit Intake & 0.117 & 0.049 \\
\hline Vegetable Intake & 0.219 & 0.015 \\
\hline \multicolumn{3}{|l|}{ Satisfaction with Current Weight } \\
\hline Body Mass Index & $0.522^{\mathrm{b}}$ & $0.581^{b}$ \\
\hline Body Fat Percentage & $0.598^{\mathrm{b}}$ & $0.646^{\mathrm{b}}$ \\
\hline Waist Circumference & $0.497^{\mathrm{b}}$ & $0.627^{\mathrm{b}}$ \\
\hline \multicolumn{3}{|l|}{$\begin{array}{l}\text { Description of Current Weight (Very Underweight to Very } \\
\text { Overweight) }\end{array}$} \\
\hline Body Mass Index & $0.739^{\mathrm{b}}$ & $0.768^{\mathrm{b}}$ \\
\hline Satisfaction with Current Weight & $0.696^{\mathrm{b}}$ & $0.690^{\mathrm{b}}$ \\
\hline Importance of Eating Healthy & -0.167 & -0.143 \\
\hline \multicolumn{3}{|l|}{ Current Weight Loss Attempts } \\
\hline Body Mass Index & $-0.416^{\mathrm{a}}$ & $-0.478^{b}$ \\
\hline Description of Current Weight & $-0.582^{b}$ & -0.636 \\
\hline Satisfaction with Current Weight & -0.068 & 0.086 \\
\hline $\begin{array}{l}\text { Confidence in Eating at Least } 2 \text { Servings of Fruit per Day } \\
\text { Fruit Intake }\end{array}$ & $-0.386^{\mathrm{a}}$ & -0.244 \\
\hline $\begin{array}{l}\text { Confidence in Eating at Least } 3 \text { Servings of Vegetables per Day } \\
\text { Vegetable Intake }\end{array}$ & $-0.447^{\mathrm{b}}$ & $-0.506^{\mathrm{b}}$ \\
\hline $\begin{array}{l}{ }^{\mathrm{a}} \text { Correlation is significant at the } 0.05 \text { level (2-tailed) } \\
\mathrm{b} \text { Correlation is significant at the } 0.01 \text { level (2-tailed) }\end{array}$ & & \\
\hline
\end{tabular}

The same variables used to determine correlations among all participants were used to determine correlations among the intervention group and control group individually (Table 12 and Table 13, respectively). Among the intervention participants ( $n=19)$, the participants' 
residence (on campus or off campus) was significantly correlated with BMI before and after the program $(\mathrm{r}=0.508, \mathrm{p}=.05$ and $\mathrm{r}=0.508, \mathrm{p}=.05$ respectively). The participants' satisfaction with current weight and actual BMI were significantly correlated before and after the program $(\mathrm{r}=0.727, \mathrm{p}=.01$ and $\mathrm{r}=0.588, \mathrm{p}=.01$ respectively). Actual body fat percentage and the participants' satisfaction with current weight were also significantly correlated before and after the program ( $\mathrm{r}=0.697, \mathrm{p}=.01$ and $\mathrm{r}=0.715, \mathrm{p}=.01$ respectively). Current weight satisfaction showed a significant correlation with actual waist circumference before and after the program $(r=0.545, p=.05$ and $r=0.561, p=.05$ respectively). The BMIs of the intervention participants were significantly correlated with descriptions of their weights before and after completion of the program ( $\mathrm{r}=0.862, \mathrm{p}=.01$ and $\mathrm{r}=0.872, \mathrm{p}=.01$ respectively). The participants' satisfaction with current weight and description of weight were also significantly correlated before and after the program $(\mathrm{r}=0.736, \mathrm{p}=.01$ and $\mathrm{r}=0.645, \mathrm{p}=.01$ respectively). Again, these correlations imply that students perceive their weight statuses correctly. This group showed a significant negative correlation between indication of actively trying to lose weight and actual BMI status before and after the program $(\mathrm{r}=-0.660, \mathrm{p}=0.01$ and $\mathrm{r}=-0.689, \mathrm{p}=0.01$ respectively) which means that those students trying to lose weight have higher BMIs than those not trying to lose weight. 
Table 12 Correlations of BUCS: Live Well Intervention Group Participants $(\mathrm{n}=19)$

\begin{tabular}{|c|c|c|}
\hline Variables & $\begin{array}{l}\text { Before } \\
\text { Program }(r)\end{array}$ & $\begin{array}{l}\text { After } \\
\text { Program }(r)\end{array}$ \\
\hline \multicolumn{3}{|l|}{ Residence (On-campus or Off-campus) } \\
\hline Body Mass Index & $0.508^{\mathrm{a}}$ & $0.508^{\mathrm{a}}$ \\
\hline Fruit Intake & 0.200 & 0.084 \\
\hline Vegetable Intake & 0.192 & 0.072 \\
\hline \multicolumn{3}{|l|}{ Satisfaction with Current Weight } \\
\hline Body Mass Index & $0.727^{\mathrm{b}}$ & $0.588^{\mathrm{b}}$ \\
\hline Body Fat Percentage & $0.697^{\mathrm{b}}$ & $0.715^{\mathrm{b}}$ \\
\hline Waist Circumference & $0.545^{\mathrm{a}}$ & $0.561^{\mathrm{a}}$ \\
\hline \multicolumn{3}{|l|}{ Description of Current Weight (Very Underweight to Very } \\
\hline Body Mass Index & $0.862^{\mathrm{b}}$ & $0.872^{\mathrm{b}}$ \\
\hline Satisfaction with Current Weight & $0.736^{\mathrm{b}}$ & $0.645^{\mathrm{b}}$ \\
\hline Importance of Eating Healthy & -0.202 & -0.050 \\
\hline Classification & 0.109 & 0.103 \\
\hline \multicolumn{3}{|l|}{ Current Weight Loss Attempts } \\
\hline Body Mass Index & $-0.660^{b}$ & $-0.689^{b}$ \\
\hline Description of Current Weight & $-0.712^{b}$ & $-0.561^{\mathrm{a}}$ \\
\hline Satisfaction with Current Weight & $-0.618^{b}$ & $-0.655^{b}$ \\
\hline \multicolumn{3}{|l|}{ Caloric Limitations for Weight Maintenance or Weight Loss } \\
\hline Body Mass Index & -0.168 & -0.147 \\
\hline Satisfaction with Current Weight & 0.044 & -0.075 \\
\hline \multicolumn{3}{|l|}{ Confidence in Eating at Least 3 Servings of Vegetables per Day } \\
\hline $\begin{array}{c}\text { Waist Circumference } \\
\text { Body Mass Index }\end{array}$ & $0.797^{\mathrm{b}}$ & $0.861^{\mathrm{b}}$ \\
\hline
\end{tabular}

Among the control group program participants, there was a significant correlation between the participants' description of weight and the participants' actual BMI before and after the program ( $r=0.750, p=0.01$ and $r=0.822, p=0.01$ respectively). The participants' body fat percentage and indicated weight satisfaction were significantly correlated before and after the program ( $\mathrm{r}=0.555, \mathrm{p}=0.05$ and $\mathrm{r}=0.622$ and $\mathrm{p}=0.01$ respectively). Weight satisfaction was also significantly correlated with waist circumference and weight description. Waist circumference 
and weight satisfaction were significantly correlated before and after the program $(r=0.563$, $\mathrm{p}=0.05$ and $\mathrm{r}=0.710, \mathrm{p}=0.01$ respectively). Weight satisfaction and weight description were significantly correlated $(\mathrm{r}=0.685, \mathrm{p}=0.05$ and $\mathrm{r}=0.757, \mathrm{p}=0.01$ respectively) before and after the program. After the program, control participants showed a significant correlation between their description of actual weight and previous weight loss attempts ( $r=0.732, p=0.01)$. Control participants also have an accurate self-perception of weight status.

Table 13 Correlations of BUCS: Live Well Control Group Participants ( $\mathrm{n}=18)$

\begin{tabular}{|c|c|c|}
\hline Variables & $\begin{array}{l}\text { Before } \\
\text { Program }(r)\end{array}$ & $\begin{array}{l}\text { After } \\
\text { Program }(r)\end{array}$ \\
\hline \multicolumn{3}{|l|}{ Residence (On-campus or Off-campus) } \\
\hline Body Mass Index & -0.197 & -0.195 \\
\hline Fruit Intake & 0.034 & 0.000 \\
\hline Vegetable Intake & 0.228 & -0.094 \\
\hline \multicolumn{3}{|l|}{ Satisfaction with Current Weight } \\
\hline Body Mass Index & $0.521^{\mathrm{a}}$ & $0.609^{\mathrm{b}}$ \\
\hline Body Fat Percentage & $0.555^{\mathrm{a}}$ & $0.622^{\mathrm{b}}$ \\
\hline Waist Circumference & $0.563^{\mathrm{a}}$ & $0.710^{\mathrm{b}}$ \\
\hline \multicolumn{3}{|l|}{$\begin{array}{l}\text { Description of Current Weight (Very Underweight to Very } \\
\text { Overweight) }\end{array}$} \\
\hline Body Mass Index & $0.750^{\mathrm{b}}$ & $0.822^{\mathrm{b}}$ \\
\hline Satisfaction with Current Weight & $0.685^{\mathrm{b}}$ & $0.757^{\mathrm{b}}$ \\
\hline Importance of Eating Healthy & -0.164 & -0.310 \\
\hline \multicolumn{3}{|l|}{ Current Weight Loss Attempts } \\
\hline Body Mass Index & -0.318 & -0.434 \\
\hline Description of Current Weight & -0.456 & $-0.732^{b}$ \\
\hline Satisfaction with Current Weight & $-0.534^{a}$ & $-0.813^{b}$ \\
\hline \multicolumn{3}{|l|}{ Confidence in Eating at Least 2 Servings of Fruit per Day } \\
\hline $\begin{array}{l}\text { Confidence in Eating at Least } 3 \text { Servings of Vegetables per Day } \\
\text { Vegetable Intake }\end{array}$ & $-0.645^{b}$ & 0.444 \\
\hline $\begin{array}{l}{ }^{\mathrm{a}} \text { Correlation is significant at the } 0.05 \text { level (2-tailed) } \\
\mathrm{b} \text { Correlation is significant at the } 0.01 \text { level (2-tailed) }\end{array}$ & & \\
\hline
\end{tabular}

The postevaluation of the intervention group asked participants if the BUCS: Live Well program met or exceeded their expectations. Of the 19 responses, 52.6\% reported they agree and 15.8\% reported they strongly agree with the statement (Table 14). There was not a significant 
change in BMI weight status or increased intake of fruits, vegetables, and whole grains but the participants were still satisfied with the program.

Table 14 Survey Response on Program Success from BUCS: Live Well Intervention Final Participants $(\mathrm{n}=19)$

\begin{tabular}{|c|c|c|}
\hline $\begin{array}{l}\text { This Program Met or Exceeded my } \\
\text { Expectations }\end{array}$ & Frequency (n) & Percentage (\%) \\
\hline 1. Strongly Disagree & 0 & 0 \\
\hline 2. Disagree & 2 & 10.5 \\
\hline 3. Undecided & 4 & 21.1 \\
\hline 4. Agree & 10 & 52.6 \\
\hline 5. Strongly Agree & 3 & 15.8 \\
\hline
\end{tabular}




\section{CHAPTER 5}

\section{DISCUSSION AND CONCLUSION}

\section{$\underline{\text { Discussion }}$}

Students reported better dietary choices after completing the program in both the total number of control and intervention participants combined and in the intervention participants alone, indicating successful components of the program. Weight status was not one of the positive results; the number of participants classified as having a normal BMI and being classified as within a normal weight range decreased by one after the completion of the program. The program may have prevented some individuals from gaining weight, but it did not prevent all of them from weight gain nor did it encourage weight loss. Weight loss alone was not the purpose of the program. Often implementing positive dietary habits and participating in regular exercise do result in weight loss, but this is not always the case. It is interesting to note that the BMI range of those completing the program was actually wider than those not completing the program. This implies that the interest level and desire to complete a health promotion program is not dependent upon the individual's current weight status.

Attitudes about dietary habits are a crucial element to initiating positive lifestyle changes. After completing the program the percentage of students stating that they felt somewhat dissatisfied in their energy and feeling healthy decreased in the total completion group. The number of participants reporting that they were somewhat satisfied or very satisfied in their energy and feeling healthy also increased after the program. Satisfaction in energy and feeling healthy is significant because these feelings alone are often the first result of implementing healthy lifestyle changes. Weight loss may not occur until weeks or months after making consistent positive dietary choices but feeling healthy and higher energy levels can result 
quickly. Participants of BUCS: Live Well may not have lost weight but after the program they felt healthier with more energy, which means the program may have initiated changes that could lead to weight loss in the future. Another attitude assessed during the program was feeling satisfied with current weight status. The percentage of those claiming they were satisfied with their weight increased after the program while those saying they were strongly satisfied with their weight decreased. A decreased satisfaction in weight could be caused by a realization that certain weight statuses, such as being obese, have negative health implications. Decreased satisfaction may not be entirely caused by weight gain. Those completion group participants claiming that it is very easy to eat a little less each day increased. Having confidence in one's ability to eat a little less each day is the first step in actually doing so. Those claiming that they were currently limiting caloric intake, planning on limiting caloric intake, and have been limiting caloric intake increased after the program. This implies that the program either initiated limiting caloric intake or continued supporting those participants already doing so. After the program, the percentage of students claiming they were too busy to eat healthy foods decreased showing that attitudes about eating healthier foods while maintaining a busy academic schedule changed during the program. More students also reported that eating healthy does not take too much time after the program.

Specific dietary habits were assessed to define what positive dietary changes were implemented. Participants from the intervention group reported that their confidence to eat at least 2 servings of fruit a day, eat at least 3 servings of vegetables a day, and eat breakfast on most days improved after the program. Confidence to make these specific dietary changes is necessary in order to implement them. However, a significant finding assessing the correlation between confidence to improve vegetable intake and actual vegetable intake suggests that 
confidence to improve intake does not necessarily mean that intake will improve. Students were asked about their fruit and vegetable consumption in 2 different portions of the survey. From the completion group, the percentage of participants consuming 4 servings of fruit and 4 servings of vegetables each day increased after the program. However, the percentage of participants consuming fruit daily decreased after the program while the percentage of those consuming vegetables daily did not change. The increase in servings of fruits and vegetables each day could be caused by the students already consuming daily fruits and vegetables before the program increasing their number of daily servings after the program. Those discontinuing consumption of fruit daily may have decreased to multiple times a week instead of discontinuing fruit consumption entirely. Among the intervention participants, the percentage of participants consuming 4 servings of fruit and 4 servings of vegetables a day increased after the program. However, the daily consumption of fruit increased while the daily consumption of vegetables decreased. This again could be a result of those already consuming daily fruits and vegetables changing the number of servings they consume each day. The control participants also reported an increase in the percentage of those consuming 4 servings of fruit and 4 serving of vegetables each day. The program may have caused the participants to want to follow a more healthful diet regardless of nutrition education components.

Significant correlations between weight status, satisfaction with weight status, body fat percentage, and weight description imply that the completion participants had an accurate perception of their weight status. In other words, those at an unhealthy weight were not satisfied with their weight and those at a healthy weight were satisfied with their weight. Accurate weight perception is significant because those needing health promotion programs for a healthier lifestyle or weight loss know that they need it. Those promoting healthy lifestyle programs do 
not need to convince overweight individuals that they are overweight and need to change, they need to create a program that is inviting to and supportive of these individuals. No significant changes were found in the participants' descriptions of personal weight status after the program. This implies that students had an accurate perception of their weight status before the program and the program did not alter that perception. Another significant correlation showed participants with higher BMIs also reported currently trying to lose weight. Because these participants were the ones with the higher BMI statuses, it can be assumed that their weight loss attempts have been generally unsuccessful. This finding further supports the position that college students need access to healthy lifestyle programs that works for their specific needs and, if appealing, students would be willing to try that program. Among the intervention participants, a significant correlation was found between the participants' BMIs and residential status indicating that those students who live on campus have a lower BMI. This correlation was only found among a group of 19 students and would need to be assessed in larger quantities for generalizability.

Most of the intervention participants from the program reported that the program met or exceeded their expectations. The participants gave this response even though they did not achieve weight loss with the study. Therefore, BUCS: Live Well had successful components for its participants. Limitations of this study include the race and gender of the participants. Overall, $5.4 \%$ of the students who completed the program were male, while $94.6 \%$ were female. The majority of participants (94.6\%) were white. The design of the study did not include the ability to ensure that students truly watched the videos and had appropriate exposure to the education materials. There was no way to determine if the participants read all the education materials. The anthropometric assessment was not self-reported, although all other data gathered from the questionnaires were. The research findings would be more applicable to other institutions if the 
participants were all in one age group and were all undergraduate students. There were a small number of participants and $41.7 \%$ of the participants were nutrition majors who are biased in their nutrition-related beliefs and practices. The conclusion of the program, including the final questionnaire and anthropometric assessment, took place during the last week of regular academic classes before finals. More students may have completed the program if the timing of the final data collection were more convenient for the students.

\section{$\underline{\text { Conclusion }}$}

College-age students have poor dietary intake and a history of weight gain that contributes to the obesity epidemic. The dietary patterns of ETSU students are representative of the dietary patterns of college students across the United States in that they are low in fruit and vegetable intake. College students are considered 'emerging adults' and are experiencing the last opportunity for formal education about nutrition and its implication on health, as they are making decisions autonomously for the first time. It is during 'emerging adulthood' that health promotion programs would be most beneficial to evoke behavior change to improve lifestyle choices. The purpose of BUCS: Live Well was to assess self-efficacy in ability to incorporate positive dietary changes, assess incidence in positive dietary habits after completion of the program, and determine if weight status, residence, and health perceptions influence dietary behaviors.

BUCS: Live Well was successful in promoting positive dietary changes, assessing students’ attitudes about health, and improving self-efficacy about positive dietary changes. Overall, $89.5 \%$ of the students were satisfied with the program. The program's findings in addition to its successes further support the need for a health promotion initiative available to all ETSU students. 


\section{REFERENCES}

1. Flegal KM, Carroll MD, Kit BK, Ogden CL. Prevalence of obesity and trends in the distribution of body mass index among US adults, 1999-2010. JAMA: The Journal of the American Medical Association. 2012;307(5):491-497.

2. Butler SM, Black DR, Blue CL, Gretebeck RJ. Change in diet, physical activity, and body weight in female college freshman. Am J Health Behav. 2004;28(1):24-32.

3. Gordon-Larsen P, Adair LS, Nelson MC, Popkin BM. Five-year obesity incidence in the transition period between adolescence and adulthood: The national longitudinal study of adolescent health. Am J Clin Nutr. 2004;80(3):569-575.

4. Racette SB, Deusinger SS, Strube MJ, Highstein GR, Deusinger RH. Changes in weight and health behaviors from freshman through senior year of college. J Nutr Educ Behav. 2008;40(1):39-42. doi: 10.1016/j.jneb.2007.01.001.

5. Franko DL, Cousineau TM, Trant M, et al. Motivation, self-efficacy, physical activity and nutrition in college students: Randomized controlled trial of an internet-based education program. Prev Med. 2008;47(4):369-377.

6. General S. The surgeon General's call to action to prevent and decrease overweight and obesity. US Department of Health and Human Services, Public Health Service, Office of the Surgeon General, Rockville, MD. 2001.

7. World Health Organization. Controlling the Global Obesity Epidemic. Nutrition. March 8, 2012. Available at http://www.who.int/nutrition/topics/obesity/en/. Accessed July 12, 2012. 8. Panel NOEIE. Treatment guidelines. . 1998.

9. Racette SB, Deusinger SS, Strube MJ, Highstein GR, Deusinger RH. Weight changes, exercise, and dietary patterns during freshman and sophomore years of college. J Am Coll Health. 2005;53(6):245-251. doi: 10.3200/JACH.53.6.245-251.

10. Strong KA, Parks SL, Anderson E, Winett R, Davy BM. Weight gain prevention: Identifying theory-based targets for health behavior change in young adults. J Am Diet Assoc. 2008;108(10):1708-1715. doi: 10.1016/j.jada.2008.07.007.

11. Crombie AP, Ilich JZ, Dutton GR, Panton LB, Abood DA. The freshman weight gain phenomenon revisited. Nutr Rev. 2009;67(2):83-94.

12. Levitsky DA, Halbmaier CA, Mrdjenovic G. The freshman weight gain: A model for the study of the epidemic of obesity. Int J Obes Relat Metab Disord. 2004;28(11):1435-1442. doi: 10.1038/sj.ijo.0802776.

13. Nelson TF, Gortmaker SL, Subramanian S, Cheung L, Wechsler H. Disparities in overweight and obesity among US college students. Am J Health Behav. 2007;31(4):363-373. 
14. Greaney ML, Less FD, White AA, et al. College students' barriers and enablers for healthful weight management: A qualitative study. Journal of Nutrition Education and Behavior. 2009;41(4):281-286.

15. PhD LJLC, PhD KND, BAS RJK, BAS JP. Psychosocial and environmental determinants of eating behaviors, physical activity, and weight change among college students: A qualitative analysis. Journal of American College Health. 2011;59(6):531-538.

16. Laska N, Larson NI, Neumark-Sztainer D, Story M. Dietary patterns and home food availability during emerging adulthood: Do they differ by living situation? Public Health Nutr. 2010;13(2):222-228.

17. Nelson MC, Story M, Larson NI, Neumark-Sztainer D, Lytle LA. Emerging adulthood and college-aged youth: An overlooked age for weight-related behavior change. Obesity (Silver Spring). 2008;16(10):2205-2211. doi: 10.1038/oby.2008.365.

18. Hoefkens C, Lachat C, Kolsteren P, Van Camp J, Verbeke W. Posting point-of-purchase nutrition information in university canteens does not influence meal choice and nutrient intake. Am J Clin Nutr. 2011;94(2):562-570.

19. Velazquez CE, Pasch KE, Ranjit N, Mirchandani G, Hoelscher DM. Are adolescents' perceptions of dietary practices associated with their dietary behaviors? J Am Diet Assoc. 2011;111(11):1735-1740.

20. Ogden CL, Carroll MD, Curtin LR, McDowell MA, Tabak CJ, Flegal KM. Prevalence of overweight and obesity in the united states, 1999-2004. JAMA: the journal of the American Medical Association. 2006;295(13):1549-1555.

21. Mokdad AH, Serdula MK, Dietz WH, Bowman BA, Marks JS, Koplan JP. The spread of the obesity epidemic in the united states, 1991-1998. JAMA: the journal of the American Medical Association. 1999;282(16):1519-1522.

22. Freedman MR, Waldrop J. Freshman orientation sessions can teach incoming students about healthful lifestyles. Journal of Nutrition Education and Behavior. 2011;43(1):69-70.

23. Wengreen HJ, Moncur C. Change in diet, physical activity, and body weight among youngadults during the transition from high school to college. Nutrition journal. 2009;8(1):32.

24. Matvienko O, Lewis DS, Schafer E. A college nutrition science course as an intervention to prevent weight gain in female college freshmen. J Nutr Educ. 2001;33(2):95-101.

25. PhD DJH, Peggy Policastro MS R, Quick V, PhD SKL. Changes in body weight and fat mass of men and women in the first year of college: A study of the" freshman 15". Journal of American College Health. 2006;55(1):41-46. 
26. U.S. Department of Health and Human Services. Healthy People 2010: Understanding and Improving Health, Volume I. Educational and Community Based Programs. Center for Disease Control and Prevention, Health Resources and Services Administration. November 2000.

Available at http://www.healthypeople.gov/2010/Document/HTML/Volume1/07Ed.htm\#_Toc490550856. Accessed August 15, 2012.

27. Demory-Luce D, Morales M, Nicklas T, Baranowski T, Zakeri I, Berenson G. Changes in food group consumption patterns from childhood to young adulthood: The bogalusa heart study. J Am Diet Assoc. 2004;104(11):1684-1691. doi: 10.1016/j.jada.2004.07.026.

28. Brunt AR, Rhee YS. Obesity and lifestyle in US college students related to living arrangemeents. Appetite. 2008;51(3):615-621.

29. Ha EJ, Caine-Bish N. Effect of nutrition intervention using a general nutrition course for promoting fruit and vegetable consumption among college students. Journal of Nutrition Education and Behavior. 2009;41(2):103-109.

30. American College Health Association. American college health association-national college health assessment spring 2008 reference group data report (abridged): The american college health association. J Am Coll Health. 2009;57(5):477-488. doi: 10.3200/JACH.57.5.477-488.

31. Hertzler AA, Webb R, Frary RB. Over consumption of fat by college students: The fast food connection. Ecol Food Nutr. 1995;34(1):49-57.

32. Lien N, Lytle LA, Klepp KI. Stability in consumption of fruit, vegetables, and sugary foods in a cohort from age 14 to age 21. Prev Med. 2001;33(3):217-226. doi: 10.1006/pmed.2001.0874.

33. Pliner $\mathrm{P}$, Saunders T. Vulnerability to freshman weight gain as a function of dietary restraint and residence. Physiol Behav. 2008;93(1-2):76-82.

34. Wynn A. Inequalities in nutrition. Nutrition and Health. 1987;5(1-2):79-94

35. Georgiou CC, Betts NM, Hoerr SL, et al. Among young adults, college students and graduates practiced more healthful habits and made more healthful food choices than did nonstudents. J Am Diet Assoc. 1997;97(7):754-759.

36. Lewis CE, Jacobs Jr DR, McCreath H, et al. Weight gain continues in the 1990s: 10-year trends in weight and overweight from the CARDIA study. Am J Epidemiol. 2000;151(12):11721181.

37. Vella-Zarb RA, Frank J, PhD E. The 'freshman 5': A meta-analysis of weight gain in the freshman year of college. Journal of American College Health. 2009;58(2):161-166. 
38. Hill JO, Wyatt HR, Reed GW, Peters JC. Obesity and the environment: Where do we go from here? Science. 2003;299(5608):853-855.

39. Anderson DA, Shapiro JR, Lundgren JD. The freshman year of college as a critical period for weight gain: An initial evaluation. Eat Behav. 2003;4(4):363-367. doi: 10.1016/S14710153(03)00030-8.

40. Lloyd-Richardson EE, Bailey S, Fava JL, Wing R. A prospective study of weight gain during the college freshman and sophomore years. Prev Med. 2009;48(3):256-261.

41. Graham MA, Jones AL. Freshman 15: Valid theory or harmful myth? Journal of American College Health. 2002;50(4):171-173.

42. Murashima M, Hoerr SL, Hughes SO, Kattelmann KK, Phillips BW. Maternal parenting behaviors during childhood relate to weight status and fruit and vegetable intake of college students. Journal of Nutrition Education and Behavior. 2011.

43. Weidner G, Kohlmann CW, Dotzauer E, Burns LR. The effects of academic stress on health behaviors in young adults. Anxiety, Stress, Coping. 1996;9(2):123-133.

44. Searles R, Terry R, Amos R. Nutrition knowledge and body-image satisfaction of female adolescents. J Nutr Educ. 1986;18.

45. Nelson MC, Kocos R, Lytle LA, Perry CL. Understanding the perceived determinants of weight-related behaviors in late adolescence: A qualitative analysis among college youth. Journal of nutrition education and behavior. 2009;41(4):287-292.

46. Cluskey M, Grobe D. College weight gain and behavior transitions: Male and female differences. J Am Diet Assoc. 2009;109(2):325-329.

47. Larson NI, Neumark-Sztainer D, Hannan PJ, Story M. Family meals during adolescence are associated with higher diet quality and healthful meal patterns during young adulthood. $J \mathrm{Am}$ Diet Assoc. 2007;107(9):1502-1510. doi: 10.1016/j.jada.2007.06.012.

48. Jakobovits C, Halstead P, Kelley L, Roe DA, Young CM. Eating habits and nutrient intakes of college women over a thirty-year period. J Am Diet Assoc. 1977;71(4):405-411.

49. Brevard PB, Ricketts CD. Residence of college students affects dietary intake, physical activity, and serum lipid levels. J Am Diet Assoc. 1996;96(1):35-38.

50. Driskell JA, Kim YN, Goebel KJ. Few differences found in the typical eating and physical activity habits of lower-level and upper-level university students. J Am Diet Assoc. 2005;105(5):798-801. doi: 10.1016/j.jada.2005.02.004.

51. Larson N, Laska MN, Story M, Neumark-Sztainer D. Predictors of fruit and vegetable intake in young adulthood. Journal of the Academy of Nutrition and Dietetics. 2012. 
52. Lowry R, Galuska DA, Fulton JE, Wechsler H, Kann L, Collins JL. Physical activity, food choice, and weight management goals and practices among US college students. Am J Prev Med. 2000;18(1):18-27.

53. Arnett JJ. Emerging adulthood: A theory of development from the late teens through the twenties. Am Psychol. 2000;55(5):469.

54. Holli BB, Calabrese RJ, Maillet JOS. Communication and education skills for dietetics professionals. XYZ editeur/XYZ Publishing; 2003.

55. Prochaska JO, Redding CA, Evers KE. The transtheoretical model and stages of change. Health behavior and health education, Theory, Research and Practice. 2008;4.

56. Bandura A. Health promotion by social cognitive means. Health Education \& Behavior. 2004;31(2):143-164.

57. Bandura A. Exercise of personal and collective efficacy in changing societies. Self-efficacy in changing societies. 1995;15:334.

58. Poddar KH, Hosig KW, Anderson ES, Nickols-Richardson SM, Duncan SE. Web-based nutrition education intervention improves self-efficacy and self-regulation related to increased dairy intake in college students. J Am Diet Assoc. 2010;110(11):1723-1727.

59. Schnoll R, Zimmerman BJ. Self-regulation training enhances dietary self-efficacy and dietary fiber consumption. J Am Diet Assoc. 2001;101(9):1006-1011. doi: 10.1016/S00028223(01)00249-8.

60. Ha EJ, Caine-Bish N. Interactive introductory nutrition course focusing on disease prevention increased whole-grain consumption by college students. Journal of Nutrition Education and Behavior. 2011.

61. Bates R, Khasawneh S. Self-efficacy and college students' perceptions and use of online learning systems. Comput Hum Behav. 2007;23(1):175-191.

62. Kenny AJ. Interaction in cyberspace: An online focus group. J Adv Nurs. 2005;49(4):414422.

63. Barnett NP, Murphy JG, Colby SM, Monti PM. Efficacy of counselor vs. computer-delivered intervention with mandated college students. Addict Behav. 2007;32(11):2529-2548.

64. Fox FE, Morris M, Rumsey N. Doing synchronous online focus groups with young people. Qual Health Res. 2007;17(4):539-547.

65. Gow RW, Trace SE, Mazzeo SE. Preventing weight gain in first year college students: An online intervention to prevent the "freshman fifteen". Eating Behav. 2010;11(1):33-39. 
66. Robert G. My student body: Effects of an internet-based prevention program to decrease obesity among college students. Journal of American College Health. 2012;60(4):324-330.

67. Leahey TM, LaRose JG, Fava JL, Wing RR. Social influences are associated with BMI and weight loss intentions in young adults. Obesity. 2010;19(6):1157-1162.

68. Napolitano MA, Hayes S, Bennett GG, Ives AK, Foster GD. Using facebook and text messaging to deliver a weight loss program to college students. Obesity. 2012.

69. Park H, Rodgers S, Stemmle J. Health organizations' use of facebook for health advertising and promotion. Health. 2011;12(1).

70. American College Health Association. Healthy campus 2010 manual. Baltimore, MD. 2002.

71. Clifford D, Anderson J, Auld G, Champ J. Good grubbin': Impact of a TV cooking show for college students living off campus. Journal of Nutrition Education and Behavior.

2009;41(3):194-200.

72. Nelson MC, Lytle LA, Pasch KE. Improving literacy about energy-related issues: The need for a better understanding of the concepts behind energy intake and expenditure among adolescents and their parents. J Am Diet Assoc. 2009;109(2):281-287.

73. Desai MN, Miller WC, Staples B, Terrill Bravender MD M. Risk factors associated with overweight and obesity in college students. Journal of American College Health.

2008;57(1):109-114.

74. Betts NM, Amos RJ, Keim K, Peters P, Stewart B. Ways young adults view foods. J Nutr Educ. 1997;29(2):73-79.

75. Division of Nutrition, Physical Activity, and Obesity. National Center for Chronic Disease Prevention and Health Promotion. About BMI for Adults. Center for Disease Control and Prevention. September 13, 2011. Available at http://www.cdc.gov/healthyweight/assessing/bmi/adult_bmi/index.html. Accessed August 15, 2012.

76. Charney P, Malone A. American Dietetic Association Pocket Guide to Nutrition Assessment. 2nd ed. Chicago, IL: American Dietetic Association; 2008.

77. Gallagher D, Visser M, Sepulveda D, Pierson R, Harris T, Heymsfield S. How useful is body mass index for comparison of body fatness across age, sex, and ethnic groups. The American Journal of Epidemiology. 1996;143(3):228-239.

78. Kuezmarski RJ, Flegal KM. Criteria for definition of overweight in transition: background and recommendation for the United States. Am J Clin Nutr. 2000;72(5):1074-1081. 
79. United States Department of Agriculture. Center for Nutrition Policy and Promotion. What's On Your Plate. Choose My Plate. August 2011. Available at http://www.choosemyplate.gov/downloads/mini_poster_English_final.pdf. Accessed January 2013.

80. United States Department of Agriculture. Center for Nutrition Policy and Promotion. Executive Summary. Dietary Guidelines for Americans 2010. Available at http://www.cnpp.usda.gov/Publications/DietaryGuidelines/2010/PolicyDoc/ExecSumm.pdf. Accessed January 2013. 


\section{APPENDIXES}

\section{APPENDIX A}

\section{$\underline{\text { Informed Consent Form and Preevaluation Questionnaire: Control }}$}

\section{Bucs: Live Well}

\section{(A Health and Wellness Program for ETSU Students)}

Thank you for supporting our research and program development by completing this survey. We realize your time is valuable and we appreciate your participation. The purpose of this research study is to provide 12 weeks of education and tools to assist students to make positive lifestyle behaviors such as healthy eating behaviors and increasing physical activity. You have been selected to participate in the control group. The procedures for the control group include: taking a survey (this will take about 15 minutes of your time) and completing body measurements (height, weight, waist circumference, BMI, and \% of Body Fat) and this will take about 10 minutes of your time. Twelve weeks later you will another survey ( 15 minutes) and complete body measurements ( 10 minutes). Once you have completed all these requirements then you will be awarded $\$ 25.00$. You must provide your name, address, and social security number in order to receive your $\$ 25.00$.

Your participation in this research experiment is voluntary. You may refuse to participate. You can quit at any time. If you quit or refuse to participate, the benefits or treatment to which you are otherwise entitled will not be affected. You may quit by contacting Dr. Michelle Lee at 423-439-7524 or leem12@etsu.edu. For questions, comments or concerns, please contact Dr. Michelle Lee at 423-4397524 or leem12@etsu.edu. You may contact the ETSU Institutional Review Board at 423-439-6054 for any questions you may have about your rights as a research subject. By continuing to answer the questions in the rest of the survey, you confirm that you have read this document.

ID \#

Scale \#

Weight

Height

BMI

Waist Circumference

\% Body Fat

1. Gender: Male

Female

2. Current Age:

3. Race: __ White Black (African American) Hispanic Other

4. Classification: Freshman Sophomore Junior Senior Graduate Student 
5. Where do you live? __ On Campus _ _ Off Campus

6. Besides being a full-time ETSU student, are you employed? __ Yes _ _ No If yes, how many hours per week do you work? hours/week

7. Are you currently taking medication for: __ high blood pressure __ high cholesterol diabetes

8. Please rate how satisfied you feel with the following aspects of your daily life:

1=Very Dissatisfied 2=Somewhat Dissatisfied 3=Neutral 4=Somewhat Satisfied 5=Very Satisfied Mood/emotion

Self-esteem

Confidence/self-assurance

Energy and feeling healthy

Your appearance

Physical mobility and physical activity

Overall quality of life

9. I am satisfied with my weight.

strongly agree

agree

neutral

disagree

strongly disagree

10. How would you describe your weight?

very underweight

slightly underweight

about the right weight

slightly overweight

very overweight

11. Are you currently trying to lose weight?

Yes No

12. Thinking about ways to lose weight, how easy or difficult is it for you to eat a little less each day? very difficult

somewhat difficult

neither difficult or easy

somewhat easy

very easy 
13. Do you consistently limit your daily calorie intake to maintain your current weight or to lose weight?

Yes, I have been for 6 months or longer

Yes, I have but for less than 6 months

No, but I intend to in the next 30 days

No, but I intend to in the next 6 months

No, and I do NOT intend to in the next 6 months

14. How important is it to you to "eat healthy" each day?

extremely not important

not important

neither important nor unimportant

somewhat important

extremely important

15. On average, how many servings of fruit do you eat daily? ( 1 serving $=1$ whole fresh fruit of $1 / 2$ cup canned or $1 / 2$ cup juice)

${ }^{0}{ }^{1}{ }^{1}{ }^{2}{ }^{3} \_4-5 \_6$ or more

16. On average, how many servings of vegetables do you eat daily? ( 1 serving $=1 / 2$ cup cooked or 1 cup raw)

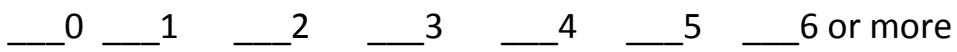

17. I actively try to avoid high salt foods.

Yes

No

18. I actively try to avoid high total fat foods.

Yes

No

19. Think about your usual eating habits over the past 30 days. How often do you eat each of the following foods and beverages?

a. Regular sodas:

Daily _ 4-6 times/week __ 1-3 times/week _once/month _ _ never _ not sure

b. Diet sodas:

Daily _ 4-6 times/week __ 1-3 times/week _ _once/month _ _ never _ not sure

c. Sweet Tea:

Daily _ 4-6 times/week __ 1-3 times/week _ once/month _ _ never _ not sure

d. Unsweetened Tea:

Daily _ 4-6 times/week _ _-3 times/week __once/month _ _ never _ _ not sure

e. Energy drinks or flavored waters:

Daily _ 4-6 times/week __ 1-3 times/week _ once/month __never _ not sure

f. Alcoholic drinks/beer/wine:

Daily _ 4-6 times/week __ 1-3 times/week _ _once/month _ never _ not sure

g. Fruit (fresh, frozen, canned or juice):

Daily __ 4-6 times/week __1-3 times/week _ _once/month __never _ _ not sure

h. Green salad:

Daily _ 4-6 times/week __ 1-3 times/week

once/month __ never __ not sure 
i. $\quad$ French fries and/or fried potatoes: Daily _ 4-6 times/week
1-3 times/week once/month never not sure

j. Vegetables (not including green salad or French fries or fried potatoes): Daily _ 4-6 times/week 1-3 times/week once/month never __ not sure

k. Potato chips: Daily _ 4-6 times/week __1-3 times/week _ once/month _ _ never _ _ not sure

I. Baked crackers: Daily __ 4-6 times/week __ 1-3 times/week __once/month __ never __ not sure

m. Baked chips: Daily _ 4-6 times/week __ 1-3 times/week _ _once/month _ _ never _ _ not sure

n. White bread: Daily _ 4-6 times/week _ _ 1-3 times/week _ once/month __ never _ _ not sure

o. Whole grain breads: Daily _ 4-6 times/week __1-3 times/week _ _once/month _ _ never _ _ not sure p. Pasta: Daily 4-6 times/week 1-3 times/week once/month never not sure

q. Whole grain pasta: Daily __ 4-6 times/week __ 1-3 times/week __once/month __ never __ not sure

r. Sweets/candies/cookies/desserts: Daily __ 4-6 times/week 1-3 times/week once/month never not sure

20. I am too busy to eat healthy foods. strongly agree agree neutral disagree strongly disagree

21. Healthy foods cost too much. strongly agree agree neutral disagree strongly disagree

22. Eating healthy just takes too much time. strongly agree agree neutral disagree strongly disagree 
23. How confident are you that you could eat at least 2 servings of fruit per day? very confident somewhat confident neutral somewhat not confident not at all confident

24. How confident are you that you could eat at least 3 servings of vegetables (not including French fries or fried potatoes) per day? very confident somewhat confident neutral somewhat not confident not at all confident

25. How confident are you that you could limit the amount of regular sodas you drink each day? very confident somewhat confident neutral somewhat not confident not at all confident

26. How confident are you that you could limit how often you eat at fast-food restaurants? very confident somewhat confident neutral somewhat not confident not at all confident

27. How confident are you that you could limit the portion sizes of the food you eat? very confident somewhat confident neutral somewhat not confident not at all confident

28. How confident are you that you could eat breakfast on most days? very confident somewhat confident neutral somewhat not confident not at all confident 
29. Please indicate which best describes your level of physical activity:

I am inactive and don't plan on starting in the next 6 months

I am inactive but I'm thinking about starting in the next 6 months

I do a bit of physical activity, but not a lot

I have been doing physical activity for 6 months

I have been doing physical activity for more than 6 months

30. How important is it to you to "be physically active" each day?

extremely not important

not important

neither important nor unimportant

somewhat important

extremely important

31. Do you currently exercise regularly (ex: walking, jogging, aerobics, gym workout, bicycling, swimming, tennis) Yes

No (if answered no, skip to question 34)

32. If you answered yes to question 31, how many days a week do you exercise on average and for how long?
1 day
2 days
3 days
4 days
5 days
6 days
7 days

33. If you answered yes to question 31, how many minutes do you exercise per day on average? 0-15 minutes 16-30 minutes

31-45 minutes 46-60 minutes over 60 minutes

34. Do you currently use a pedometer?

Yes No

35. I enjoy getting regular exercise.

strongly agree

agree

neutral

disagree

strongly disagree

36. If you do not exercise regularly, which are barriers for you? (mark all that apply) lack of time self-conscious not interested environmental conditions (temperature, safety) lack of self-discipline physical/medical limitations lack of facilities/space lack of knowledge on how to exercise 
37. I am too busy to exercise. strongly agree

agree

neutral

disagree

strongly disagree

38. I do not enjoy exercising. strongly agree

agree

neutral

disagree

strongly disagree

39. How confident are you that you could exercise at least 30 minutes for $4-6$ days a week? very confident somewhat confident

neutral

somewhat not confident

not at all confident

40. What is your major?

41. What is your age?

18-25 years old

26-45 years old

46-65 years old

over 65 years old 


\section{APPENDIX B}

\section{Informed Consent Form and Preevaluation Questionnaire: Intervention}

\section{Bucs: Live Well}

\section{(A Health and Wellness Program for ETSU Students)}

Thank you for supporting our research and program development by completing this survey. We realize your time is valuable and we appreciate your participation. The purpose of this research study is to provide 12 weeks of education and tools to assist students to make positive lifestyle behaviors such as healthy eating behaviors and increasing physical activity.

The procedures, which will involve you as a research subject, include: Taking a survey (this will take about 15 minutes of your time) and completing body measurements (height, weight, waist circumference, BMI, and \% of Body Fat) and this will take about 10 minutes of your time. During the next 12 weeks you will need to listen/watch at least 10 of 12 podcasts offered as well as complete and turn in your weekly activity records (pedometer steps and physical activities). At the end of the program you will take another survey ( 15 minutes) and complete body measurements. Once you have completed all these requirements then you will be awarded $\$ 25.00$. You must provide your name, address, and social security number in order to receive your $\$ 25.00$.

Your participation in this research experiment is voluntary. You may refuse to participate. You can quit at any time. If you quit or refuse to participate, the benefits or treatment to which you are otherwise entitled will not be affected. You may quit by contacting Dr. Michelle Lee at 423-439-7524 or leem12@etsu.edu. For questions, comments or concerns, please contact Dr. Michelle Lee at 423-4397524 or leem12@etsu.edu. You may contact the ETSU Institutional Review Board at 423-439-6054 for any questions you may have about your rights as a research subject. By continuing to answer the questions in the rest of the survey, you confirm that you have read this document.

ID \#

Scale \#

Weight

Height

$\mathrm{BMI}$

Waist Circumference

\% Body Fat

1. Gender: Male

Female

2. Current Age:

3. Race: White Black (African American) Hispanic Other

4. Classification: Freshman Sophomore Junior Senior Graduate Student 
5. Where do you live? __ On Campus _ Off Campus

6. Besides being a full-time ETSU student, are you employed? __ Yes _ _ No If yes, how many hours per week do you work? hours/week

7. Are you currently taking medication for: diabetes

high blood pressure high cholesterol

8. Please rate how satisfied you feel with the following aspects of your daily life:

1=Very Dissatisfied $2=$ =Somewhat Dissatisfied $3=$ Neutral $4=$ Somewhat Satisfied $5=$ Very

Satisfied

_Mood/emotion

Self-esteem

Confidence/self-assurance

Energy and feeling healthy

Your appearance

Physical mobility and physical activity

Overall quality of life

9. I am satisfied with my weight.

strongly agree

agree

neutral

disagree

strongly disagree

10. How would you describe your weight?

_ very underweight

slightly underweight

about the right weight

slightly overweight

very overweight

11. Are you currently trying to lose weight?

Y Yes No

12. Thinking about ways to lose weight, how easy or difficult is it for you to eat a little less each day? _very difficult somewhat difficult neither difficult or easy somewhat easy

very easy 
13. Do you consistently limit your daily calorie intake to maintain your current weight or to lose weight?

_ Yes, I have been for 6 months or longer

Yes, I have but for less than 6 months

No, but I intend to in the next 30 days

No, but I intend to in the next 6 months

No, and I do NOT intend to in the next 6 months

14. How important is it to you to "eat healthy" each day?

_extremely not important

not important

neither important nor unimportant

somewhat important

extremely important

15. On average, how many servings of fruit do you eat daily? ( 1 serving $=1$ whole fresh fruit of $1 / 2$ cup canned or $1 / 2$ cup juice)
-
$0 \_1-2$
3
4
$5 \_6$ or more

16. On average, how many servings of vegetables do you eat daily? $(1$ serving $=1 / 2$ cup cooked or 1 cup raw)
- 0
1
2
3
4
$5 \_6$ or more

17. I actively try to avoid high salt foods.

_Yes_ No

18. I actively try to avoid high total fat foods.

Yes_No

19. Think about your usual eating habits. How many times a week do you eat the following foods and beverages?

a. Regular sodas:

Daily _4-6 times/week _ 1-3 times/week _once/month _ _never _ _not sure

b. Diet sodas:

Daily __ 4-6 times/week __ 1-3 times/week __once/month _ _ never _ _ not sure

c. Sweet Tea:

Daily _ 4-6 times/week_1-3 times/week

once/month

never

not sure

d. Unsweetened Tea:

Daily _ 4-6 times/week _ 1-3 times/week _once/month _ never _ not sure

e. Energy drinks or flavored waters:

Daily __ 4-6 times/week

1-3 times/week

once/month

never

not sure

f. Alcoholic drinks/beer/wine: Daily _ 4-6 times/week

1-3 times/week

once/month

never

not sure 
g. Fruit (fresh, frozen, canned or juice): Daily 4-6 times/week 1-3 times/week once/month never not sure

h. Green salad:

Daily __ 4-6 times/week __ 1-3 times/week once/month never not sure

i. French fries and/or fried potatoes: Daily _ 4-6 times/week __ 1-3 times/week _once/month __ never _ _ not sure

j. Vegetables (not including green salad or French fries or fried potatoes): Daily __ 4-6 times/week __ 1-3 times/week _ _once/month __ never __ not sure

k. Potato chips:
Daily
4-6 times/week
1-3 times/week
once/month
never
not sure

I. Baked crackers: Daily _ 4-6 times/week __ 1-3 times/week __once/month __ never __ not sure

m. Baked chips:

Daily _ 4-6 times/week __ 1-3 times/week _ _once/month _ _ never __ not sure

n. White bread:
Daily
4-6 times/week
1-3 times/week
once/month
never
not sure

o. Whole grain breads: Daily 4-6 times/week 1-3 times/week once/month never not sure

p. Pasta:

Daily _ 4-6 times/week 1-3 times/week once/month never not sure

q. Whole grain pasta: Daily _ 4-6 times/week __ 1-3 times/week _once/month _ _ never _ not sure

r. Sweets/candies/cookies/desserts:

Daily _ 4-6 times/week __ 1-3 times/week _ _once/month _ _never _ _ not sure

20. I am too busy to eat healthy foods.

strongly agree
agree
neutral
disagree
strongly disagree

21. Healthy foods cost too much.
strongly agree
__agree
neutral
disagree
strongly disagree

22. Eating healthy just takes too much time.
strongly agree
agree
neutral
disagree
strongly disagree 
23. How confident are you that you could eat at least 2 servings of fruit per day?

_very confident

somewhat confident

neutral

somewhat not confident

not at all confident

24. How confident are you that you could eat at least 3 servings of vegetables (not including French fries or fried potatoes) per day?

_very confident

somewhat confident

neutral

somewhat not confident

not at all confident

25. How confident are you that you could limit the amount of regular sodas you drink each day?

very confident

somewhat confident

neutral

somewhat not confident

not at all confident

26. How confident are you that you could limit how often you eat at fast-food restaurants?

very confident

somewhat confident

neutral

somewhat not confident

not at all confident

27. How confident are you that you could limit the portion sizes of the food you eat?

very confident

somewhat confident

neutral

somewhat not confident

not at all confident

28. How confident are you that you could eat breakfast on most days?

very confident

somewhat confident

neutral

somewhat not confident

not at all confident 
29. Please indicate which best describes your level of physical activity:

_ I am inactive and don't plan on starting in the next 6 months

I am inactive but I'm thinking about starting in the next 6 months

I do a bit of physical activity, but not a lot

I have been doing physical activity for 6 months

I have been doing physical activity for more than 6 months

30. How important is it to you to "be physically active" each day?

extremely not important

not important

neither important nor unimportant

somewhat important

extremely important

31. Do you currently exercise regularly (ex: walking, jogging, aerobics, gym workout, bicycling, swimming, tennis)

Yes _ N No (if answered no, skip to question 34)

32. If you answered yes to question 31 , how many days a week do you exercise on average and for how long?

_ 1 day _ 2 days _ 3 days _ 4 days _ 5 days _ 6 days _ 7 days

33. If you answered yes to question 31 , how many minutes do you exercise per day on average?

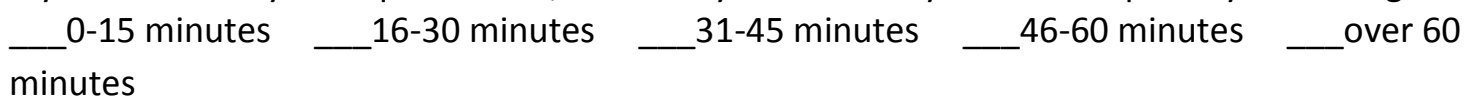

34. Do you currently use a pedometer?

Yes

No

35. I enjoy getting regular exercise.

strongly agree

agree

neutral

disagree

strongly disagree

36. If you do not exercise regularly, which are barriers for you? (mark all that apply)

_lack of time not interested lack of self-discipline lack of facilities/space self-conscious environmental conditions (temperature, safety) physical/medical limitations lack of knowledge on how to exercise 
37. I am too busy to exercise.

_strongly agree

agree

neutral

disagree

strongly disagree

38. I do not enjoy exercising.

_ strongly agree

agree

nneutral

disagree

strongly disagree

39. How confident are you that you could exercise at least 30 minutes for 4-6 days a week?

_ very confident

somewhat confident

neutral

somewhat not confident

_ not at all confident

40. What is your major?

41. What is your age?

18-25 years old

26-45 years old

46-65 years old

over 65 years old 


\section{APPENDIX C}

\section{Postevaluation Questionnaire: Control}

\section{Bucs: Live Well}

\section{(A Health and Wellness Program for ETSU Students)}

Thank you for supporting our research and program development by completing this survey. We realize your time is valuable and we appreciate your participation. The purpose of this research study was to provide 12 weeks of education and tools to assist students to make positive lifestyle behaviors such as healthy eating behaviors and increasing physical activity. You were selected to participate in the control group.

The procedures, which will involve you as a research subject, include: Taking a survey (this will take about 15 minutes of your time) and completing body measurements (height, weight, waist circumference, BMI, and \% of Body Fat) and this will take about 10 minutes of your time. If you complete the survey and body measurements at the beginning and end of this research study then you will be awarded $\$ 25.00$. Your participation in this research experiment is voluntary. You may refuse to participate. You can quit at any time. If you quit or refuse to participate, the benefits or treatment to which you are otherwise entitled will not be affected. You may quit by contacting Dr. Michelle Lee at 423-439-7524 or leeml2@etsu.edu. For questions, comments or concerns, please contact Dr. Michelle Lee at 423-439-7524 or leeml2@etsu.edu. You may contact the ETSU Institutional Review Board at 423439-6054 for any questions you may have about your rights as a research subject.

By continuing to answer the questions in the rest of the survey, you confirm that you have read this document.

ID \#

Scale \#

Weight

Height

$\mathrm{BMI}$

Waist Circumference

\% Body Fat

1. Gender: Male Female

2. Current Age:

3. Race: White Black (African American) Hispanic Other

4. Classification: Freshman Sophomore Junior Senior Graduate Student

5. Where do you live? On Campus Off Campus 
6. Besides being a full-time ETSU student, are you employed? __es No

If yes, how many hours per week do you work? hours/week

7. Are you currently taking medication for: diabetes

high blood pressure

high cholesterol

8. Please rate how satisfied you feel with the following aspects of your daily life:

1=Very Dissatisfied 2=Somewhat Dissatisfied 3=Neutral $4=$ Somewhat Satisfied $5=$ Very

Satisfied

_Mood/emotion

Self-esteem

Confidence/self-assurance

Energy and feeling healthy

Your appearance

Physical mobility and physical activity

Overall quality of life

9. I am satisfied with my weight.

strongly agree

_ agree

neutral

disagree

strongly disagree

10. How would you describe your weight?

very underweight

slightly underweight

about the right weight

slightly overweight

very overweight

11. Are you currently trying to lose weight?

Yes

No

12. Thinking about ways to lose weight, how easy or difficult is it for you to eat a little less each day?

_ very difficult

somewhat difficult

neither difficult or easy

somewhat easy

very easy 
13. Do you consistently limit your daily calorie intake to maintain your current weight or to lose weight?

_ Yes, I have been for 6 months or longer

Yes, I have but for less than 6 months

No, but I intend to in the next 30 days

No, but I intend to in the next 6 months

_No, and I do NOT intend to in the next 6 months

14. How important is it to you to "eat healthy" each day?

_extremely not important

not important

neither important nor unimportant

somewhat important

extremely important

15. On average, how many servings of fruit do you eat daily? ( 1 serving $=1$ whole fresh fruit of $1 / 2$ cup canned or $1 / 2$ cup juice)
-
$0 \_1-2$
3
4
$5 \_6$ or more

16. On average, how many servings of vegetables do you eat daily? ( 1 serving $=1 / 2$ cup cooked or 1 cup raw)
- 0
1
2
3
4
$5 \_6$ or more

17. I actively try to avoid high salt foods.

Yes

No

18. I actively try to avoid high total fat foods.

Yes

No

19. Think about your usual eating habits over the past 30 days. How often do you eat each of the following foods and beverages?

a. Regular sodas:

Daily __ 4-6 times/week __ 1-3 times/week __once/month _ _ never _ _ not sure

b. Diet sodas:

Daily _ 4-6 times/week

1-3 times/week

once/month

never

not sure

c. Sweet Tea: Daily _ 4-6 times/week

1-3 times/week once/month never __ not sure

d. Unsweetened Tea:

Daily __ 4-6 times/week 1-3 times/week once/month never not sure

e. Energy drinks or flavored waters: Daily _ 4-6 times/week 1-3 times/week once/month never not sure

f. Alcoholic drinks/beer/wine: Daily 4-6 times/week 1-3 times/week once/month never not sure 
g. Fruit (fresh, frozen, canned or juice): Daily 4-6 times/week 1-3 times/week once/month never not sure

h. Green salad:

Daily __ 4-6 times/week __ 1-3 times/week once/month never not sure

i. French fries and/or fried potatoes: Daily _ 4-6 times/week __ 1-3 times/week _once/month __ never _ _ not sure

j. Vegetables (not including green salad or French fries or fried potatoes): Daily __ 4-6 times/week __ 1-3 times/week _ _once/month __ never __ not sure

k. Potato chips:
Daily
4-6 times/week
1-3 times/week
once/month
never
not sure

I. Baked crackers: Daily _ 4-6 times/week __ 1-3 times/week __once/month __ never __ not sure

m. Baked chips:

Daily _ 4-6 times/week __ 1-3 times/week _ _once/month _ _ never __ not sure

n. White bread:
Daily
4-6 times/week
1-3 times/week
once/month
never
not sure

o. Whole grain breads: Daily 4-6 times/week 1-3 times/week once/month never not sure

p. Pasta:

Daily _ 4-6 times/week 1-3 times/week once/month never not sure

q. Whole grain pasta: Daily _ 4-6 times/week __ 1-3 times/week _once/month _ _ never _ not sure

r. Sweets/candies/cookies/desserts:

Daily _ 4-6 times/week __ 1-3 times/week _ _once/month _ _never _ _ not sure

20. I am too busy to eat healthy foods.

strongly agree
agree
neutral
disagree
strongly disagree

21. Healthy foods cost too much.
strongly agree
__agree
neutral
disagree
strongly disagree

22. Eating healthy just takes too much time.

strongly agree
agree
neutral
disagree
strongly disagree


23. How confident are you that you could eat at least 2 servings of fruit per day?

_very confident

somewhat confident

neutral

somewhat not confident

not at all confident

24. How confident are you that you could eat at least 3 servings of vegetables (not including French fries or fried potatoes) per day?

_very confident

somewhat confident

neutral

somewhat not confident

not at all confident

25. How confident are you that you could limit the amount of regular sodas you drink each day?

very confident

somewhat confident

neutral

somewhat not confident

not at all confident

26. How confident are you that you could limit how often you eat at fast-food restaurants?

very confident

somewhat confident

neutral

somewhat not confident

not at all confident

27. How confident are you that you could limit the portion sizes of the food you eat?

very confident

somewhat confident

neutral

somewhat not confident

not at all confident

28. How confident are you that you could eat breakfast on most days?

very confident

somewhat confident

neutral

somewhat not confident

not at all confident 
29. Please indicate which best describes your level of physical activity:

_ I am inactive and don't plan on starting in the next 6 months

I am inactive but I'm thinking about starting in the next 6 months

I do a bit of physical activity, but not a lot

I have been doing physical activity for 6 months

I have been doing physical activity for more than 6 months

30. How important is it to you to "be physically active" each day?

extremely not important

not important

neither important nor unimportant

somewhat important

_extremely important

31. Do you currently exercise regularly (ex: walking, jogging, aerobics, gym workout, bicycling, swimming, tennis)

Y Yes

No (if answered no, skip to question 34)

32. If you answered yes to question 31, how many days a week do you exercise on average and for how long?

1 day

2 days

3 days

4 days

5 days

6 days

7 days

33. If you answered yes to question 31 , how many minutes do you exercise per day on average?

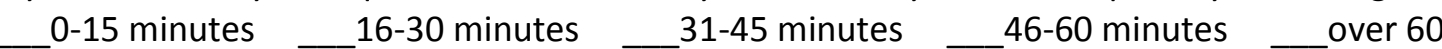
minutes

34. Do you currently use a pedometer?

_Yes_ No

35. I enjoy getting regular exercise.

strongly agree

agree

neutral

disagree

strongly disagree

36. If you do not exercise regularly, which are barriers for you? (mark all that apply)

_lack of time not interested lack of self-discipline lack of facilities/space self-conscious environmental conditions (temperature, safety) physical/medical limitations lack of knowledge on how to exercise 
37. I am too busy to exercise.

_trongly agree

$$
\begin{aligned}
& \text { _ }{ }^{\text {ngree }} \\
& \text { neutral } \\
& \text { disagree } \\
& \text { strongly disagree }
\end{aligned}
$$

38. I do not enjoy exercising.

_ strongly agree

agree

neutral

disagree

strongly disagree

39. How confident are you that you could exercise at least 30 minutes for 4-6 days a week?

_very confident

somewhat confident

_neutral

somewhat not confident

_ not at all confident

40. What is your major?

41. What is your age?

18-25 years old
26-45 years old
$46-65$ years old
over 65 years old




\section{APPENDIX D}

\section{$\underline{\text { Postevaluation Questionnaire: Intervention }}$}

\section{Bucs: Live Well}

\section{(A Health and Wellness Program for ETSU Students)}

Thank you for supporting our research and program development by completing this survey. We realize your time is valuable and we appreciate your participation. The purpose of this research study was to provide 12 weeks of education and tools to assist students to make positive lifestyle behaviors such as healthy eating behaviors and increasing physical activity.

The procedures, which will involve you as a research subject, include: Taking a survey (this will take about 15 minutes of your time) and completing body measurements (height, weight, waist circumference, BMI, and \% of Body Fat) and this will take about 10 minutes of your time. If you have listened/watched 10 of 12 podcasts and turned in your weekly physical activity records then you will be given $\$ 25.00$. You must provide your name, address, and social security number in order to receive your $\$ 25.00$. Your participation in this research experiment is voluntary. You may refuse to participate. You can quit at any time. If you quit or refuse to participate, the benefits or treatment to which you are otherwise entitled will not be affected. You may quit by contacting Dr. Michelle Lee at 423-439-7524 or leem12@etsu.edu. For questions, comments or concerns, please contact Dr. Michelle Lee at 423-4397524 or leeml2@etsu.edu. You may contact the ETSU Institutional Review Board at 423-439-6054 for any questions you may have about your rights as a research subject.

By continuing to answer the questions in the rest of the survey, you confirm that you have read this document.

ID \#

Scale \#

Weight

Height

BMI

Waist Circumference

$\%$ Body Fat

1. Gender: Male

Female

2. Current Age:

3. Race: _White Black (African American) Hispanic Other

4. Classification: Freshman Sophomore Junior Senior Graduate Student

5. Where do you live? On Campus Off Campus 
6. Besides being a full-time ETSU student, are you employed? __es No

If yes, how many hours per week do you work? hours/week

7. Are you currently taking medication for: diabetes

high blood pressure

high cholesterol

8. Please rate how satisfied you feel with the following aspects of your daily life:

1=Very Dissatisfied 2=Somewhat Dissatisfied 3=Neutral $4=$ Somewhat Satisfied $5=$ Very

Satisfied

Mood/emotion

Self-esteem

Confidence/self-assurance

Energy and feeling healthy

Your appearance

Physical mobility and physical activity

Overall quality of life

9. I am satisfied with my weight.

strongly agree

_ agree

neutral

disagree

strongly disagree

10. How would you describe your weight?

very underweight

slightly underweight

about the right weight

slightly overweight

very overweight

11. Are you currently trying to lose weight?

Yes

No

12. Thinking about ways to lose weight, how easy or difficult is it for you to eat a little less each day?

_ very difficult

somewhat difficult

neither difficult or easy

somewhat easy

very easy 
13. Do you consistently limit your daily calorie intake to maintain your current weight or to lose weight?

_ Yes, I have been for 6 months or longer

Yes, I have but for less than 6 months

No, but I intend to in the next 30 days

No, but I intend to in the next 6 months

No, and I do NOT intend to in the next 6 months

14. How important is it to you to "eat healthy" each day?

_extremely not important

not important

neither important nor unimportant

somewhat important

extremely important

15. On average, how many servings of fruit do you eat daily? ( 1 serving $=1$ whole fresh fruit of $1 / 2$ cup canned or $1 / 2$ cup juice)
-
$0 \_1-2$
3
$4-5$
6 or more

16. On average, how many servings of vegetables do you eat daily? $(1$ serving $=1 / 2$ cup cooked or 1 cup raw)
- 0
1
2
3
4
$5 \_6$ or more

17. I actively try to avoid high salt foods.

Yes No

18. I actively try to avoid high total fat foods.

Yes No

19. Think about your usual eating habits over the past 30 days. How often do you eat each of the following foods and beverages?

a. Regular sodas:

Daily _ 4-6 times/week _ 1-3 times/week _ once/month _ _never _ _not sure

a. Diet sodas:

Daily __-6 times/week __ 1-3 times/week __once/month _ _ never _ _ not sure

b. Sweet Tea:

Daily _ 4-6 times/week_ 1-3 times/week

once/month

never __ not sure

c. Unsweetened Tea:

Daily _ 4-6 times/week _ 1-3 times/week _ once/month _ never _ not sure

d. Energy drinks or flavored waters:

Daily _ 4-6 times/week

1-3 times/week

once/month

never

not sure

e. Alcoholic drinks/beer/wine: Daily _ 4-6 times/week

1-3 times/week

once/month

never

not sure 
f. Fruit (fresh, frozen, canned or juice): Daily 4-6 times/week 1-3 times/week once/month never not sure

g. Green salad:

Daily _ 4-6 times/week __ 1-3 times/week once/month never not sure

h. French fries and/or fried potatoes: Daily _ 4-6 times/week __ 1-3 times/week _once/month _ _ never _ not sure

i. Vegetables (not including green salad or French fries or fried potatoes): Daily _ 4-6 times/week __ 1-3 times/week _ _once/month _ _never _ _ not sure

j. Potato chips:
Daily
4-6 times/week
1-3 times/week
once/month
never
not sure

k. Baked crackers: Daily __ 4-6 times/week __ 1-3 times/week __once/month _ _never _ _not sure

I. Baked chips:

Daily _ 4-6 times/week 1-3 times/week once/month never not sure

m. White bread:
Daily
4-6 times/week
1-3 times/week
once/month
never
not sure

n. Whole grain breads: Daily 4-6 times/week 1-3 times/week once/month never not sure

o. Pasta:

Daily _ 4-6 times/week 1-3 times/week once/month never not sure

p. Whole grain pasta: Daily _ 4-6 times/week __ 1-3 times/week _ once/month _ never _ not sure

q. Sweets/candies/cookies/desserts:

Daily _ 4-6 times/week 1-3 times/week once/month never not sure

20. I am too busy to eat healthy foods.

strongly agree
agree
neutral
disagree
strongly disagree

21. Healthy foods cost too much.
strongly agree
__agree
neutral
disagree
strongly disagree

22. Eating healthy just takes too much time.

strongly agree
agree
neutral
disagree
strongly disagree


23. How confident are you that you could eat at least 2 servings of fruit per day?

_very confident

somewhat confident

neutral

somewhat not confident

not at all confident

24. How confident are you that you could eat at least 3 servings of vegetables (not including French fries or fried potatoes) per day?

_very confident

somewhat confident

neutral

somewhat not confident

not at all confident

25. How confident are you that you could limit the amount of regular sodas you drink each day?

very confident

somewhat confident

neutral

somewhat not confident

not at all confident

26. How confident are you that you could limit how often you eat at fast-food restaurants?

very confident

somewhat confident

neutral

somewhat not confident

not at all confident

27. How confident are you that you could limit the portion sizes of the food you eat?

very confident

somewhat confident

neutral

somewhat not confident

not at all confident

28. How confident are you that you could eat breakfast on most days?

very confident

somewhat confident

neutral

somewhat not confident

not at all confident 
29. Please indicate which best describes your level of physical activity:

_ I am inactive and don't plan on starting in the next 6 months

I am inactive but I'm thinking about starting in the next 6 months

I do a bit of physical activity, but not a lot

I have been doing physical activity for 6 months

I have been doing physical activity for more than 6 months

30. How important is it to you to "be physically active" each day?

extremely not important

not important

neither important nor unimportant

somewhat important

_extremely important

31. Do you currently exercise regularly (ex: walking, jogging, aerobics, gym workout, bicycling, swimming, tennis)

Y Yes

No (if answered no, skip to question 34)

32. If you answered yes to question 31, how many days a week do you exercise on average and for how long?

1 day

2 days

3 days

4 days

5 days

6 days

7 days

33. If you answered yes to question 31 , how many minutes do you exercise per day on average?

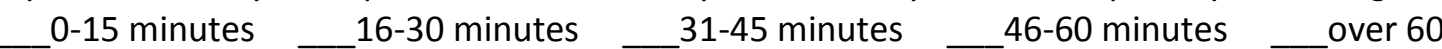
minutes

34. Do you currently use a pedometer?

Yes_No

35. I enjoy getting regular exercise.

strongly agree

agree

neutral

disagree

strongly disagree

36. If you do not exercise regularly, which are barriers for you? (mark all that apply)

_lack of time not interested lack of self-discipline lack of facilities/space self-conscious environmental conditions (temperature, safety) physical/medical limitations lack of knowledge on how to exercise 
37. I am too busy to exercise.

_trongly agree

_agree
neutral
disagree
strongly disagree

38. I do not enjoy exercising.

_ strongly agree

agree
neutral
disagree
strongly disagree

39. How confident are you that you could exercise at least 30 minutes for 4-6 days a week?

_ very confident

somewhat confident

neutral

somewhat not confident

_ not at all confident 
40. Which podcasts did you listen/watch during the 12 weeks and were they helpful? Title of Podcast Watched $\quad$ Helpful

What is Healthy Eating?

Get Moving

Show Me the Weigh

Portion Distortion

What is Your Eating Style?

Sticker Shock

What's In Your Grocery Cart?

Fad Diets

Chronic Disease and Your Health

Supplements and You

Don't Drink Your Calories

Eating Out Survival Guide

41. Did you participate in the one-on-one nutrition counseling session? Yes No

42. If you did participate did you feel it was beneficial? Comments:

43. Are there other topics we did not cover that are of interest to you?

44. This program met or exceeded my expectations?

Strongly disagree

Disagree

Undecided

Agree

Strongly Agree 
45. What suggestions do you have for improving this program?

46. What is your major?

47. What is your age?

18-25 years old

26-45 years old

46-65 years old

over 65 years old 


\section{APPENDIX E}

\section{Food Frequency Questionnaire Tables}


Food Frequency Questionnaire of Participants that Completed BUCS: Live Well from the Pre-Evaluation and Post-Evaluation (n=37)

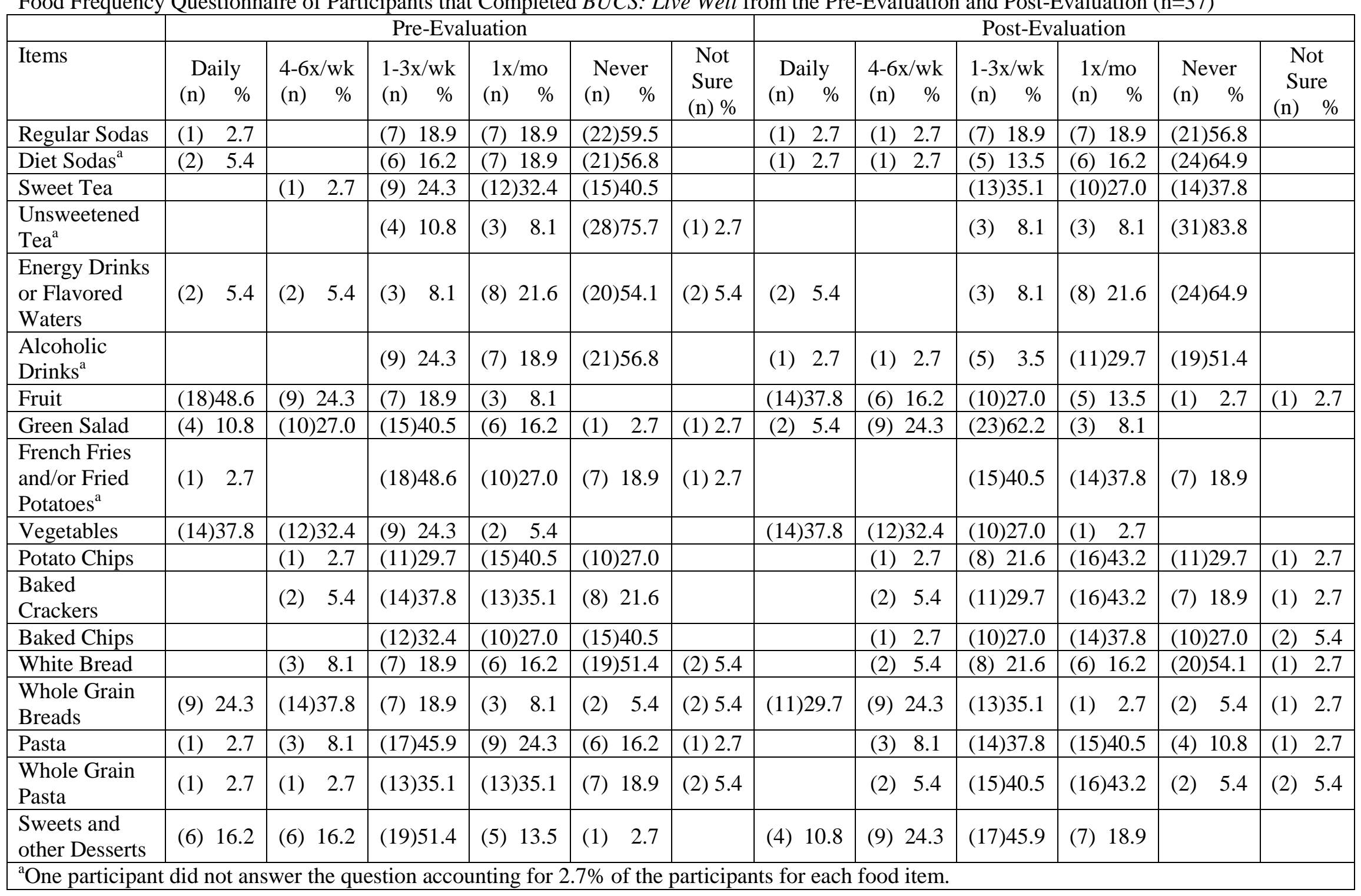


Food Frequency Questionnaire of Intervention Group BUCS: Live Well Participants from Pre-Evaluation and Post-Evaluation (n=19)

\begin{tabular}{|c|c|c|c|c|c|c|c|c|c|c|c|c|}
\hline \multirow[b]{2}{*}{ Items } & \multicolumn{6}{|c|}{ Pre-Evaluation } & \multicolumn{6}{|c|}{ Post-Evaluation } \\
\hline & $\begin{array}{l}\text { Daily } \\
\text { (n) \% }\end{array}$ & $\begin{array}{l}4-6 x / w k \\
\text { (n) \% }\end{array}$ & $\begin{array}{l}1-3 x / w k \\
\text { (n) } \%\end{array}$ & $\begin{array}{l}1 \mathrm{x} / \mathrm{mo} \\
\text { (n) } \%\end{array}$ & \begin{tabular}{l}
\multicolumn{2}{c}{ Never } \\
(n) $\%$
\end{tabular} & $\begin{array}{l}\text { Not } \\
\text { Sure } \\
\text { (n) \% }\end{array}$ & $\begin{array}{l}\text { Daily } \\
\text { (n) } \%\end{array}$ & $\begin{array}{l}4-6 x / w k \\
\text { (n) } \%\end{array}$ & $\begin{array}{l}1-3 x / w k \\
\text { (n) } \%\end{array}$ & $\begin{array}{l}1 \mathrm{x} / \mathrm{mo} \\
\text { (n) } \%\end{array}$ & \begin{tabular}{l}
\multicolumn{2}{c}{ Never } \\
(n) $\%$
\end{tabular} & $\begin{array}{l}\text { Not } \\
\text { Sure } \\
\text { (n) } \%\end{array}$ \\
\hline Regular Sodas & & & (4) 21.1 & (5) 26.3 & (10)52.6 & & & & (5) 26.3 & (3) 15.8 & (11)57.9 & \\
\hline Diet Sodas & (1) 5.3 & & (4) 21.1 & (4) 21.1 & (10)52.6 & & & (1) 5.3 & (14)21.1 & (2) 10.5 & (12)62.3 & \\
\hline Sweet Tea & & (1) 5.3 & (7) 36.8 & (4) 21.1 & (7) 36.8 & & & & (10)52.6 & (2) 10.5 & (12)62.3 & \\
\hline $\begin{array}{l}\text { Unsweetened } \\
\text { Tea }\end{array}$ & & & (3) 15.8 & (1) 5.3 & $(14) 73.7$ & (1) 5.3 & & & (1) 5.3 & (1) 5.3 & (17)89.5 & \\
\hline $\begin{array}{l}\text { Energy Drinks } \\
\text { or Flavored } \\
\text { Waters } \\
\end{array}$ & (1) 5.3 & (1) 5.3 & (2) 10.5 & (4) 21.1 & (11)57.9 & & (1) 5.3 & & & (4) 21.1 & $(14) 73.7$ & \\
\hline $\begin{array}{l}\text { Alcoholic } \\
\text { Drinks }\end{array}$ & & & (5) 26.3 & (3) 15.8 & (11)57.9 & & & & (3) 15.8 & (5) 26.3 & (11)57.9 & \\
\hline Fruit & (9) 47.4 & (5) 26.3 & (4) 21.1 & (1) 5.3 & & & (6)31.6 & (5) 26.3 & \begin{tabular}{|ll} 
(5) 26.3 \\
\end{tabular} & (3) 15.8 & & \\
\hline Green Salad & (2)10.5 & (6) 31.6 & (8) 42.1 & (3) 15.8 & & & (1) 5.3 & (6) 31.6 & (11)57.9 & (1) 5.3 & & \\
\hline $\begin{array}{l}\text { French Fries } \\
\text { and/or Fried } \\
\text { Potatoes }^{\mathrm{a}}\end{array}$ & & & (10)52.6 & (4) 21.1 & (5) 26.3 & & & & (6) 31.6 & (8) 42.1 & (4) 21.1 & \\
\hline Vegetables & (6)31.6 & (9) 47.4 & (3) 15.8 & (1) 5.3 & & & (9)47.4 & (5) 26.3 & \begin{tabular}{|ll} 
(5) 26.3 \\
\end{tabular} & & & \\
\hline Potato Chips & & & (3) 15.8 & (9) 47.4 & (7) 36.8 & & & & \begin{tabular}{|ll} 
(3) 15.8 \\
\end{tabular} & $\begin{array}{|ll|}\text { (9) } 47.4 \\
\end{array}$ & (7) 36.8 & \\
\hline $\begin{array}{l}\text { Baked } \\
\text { Crackers }\end{array}$ & & (2) 10.5 & (6) 31.6 & (8) 42.1 & (3) 15.8 & & & (1) 5.3 & (7) 36.8 & (7) 36.8 & (4) 21.1 & \\
\hline Baked Chips & & & (6) 31.6 & (6) 31.6 & (7) 36.8 & & & & \begin{tabular}{|ll} 
(5) 26.3 \\
\end{tabular} & \begin{tabular}{|ll} 
(9) & 47.4 \\
\end{tabular} & (5) 26.3 & \\
\hline White Bread & & (2) 10.5 & (4) 21.1 & (3) 15.8 & (10)52.6 & & & (1) 5.3 & (5) 26.3 & (3) 15.8 & (10)52.6 & \\
\hline $\begin{array}{l}\text { Whole Grain } \\
\text { Breads }\end{array}$ & (5)26.3 & (8) 42.1 & (4) 21.1 & & (2) 10.5 & & (8)42.1 & (5) 26.3 & (5) 26.3 & & (1) 5.3 & \\
\hline Pasta & & (3) 15.8 & $\begin{array}{ll}\text { (8) } 42.1 \\
\end{array}$ & (4) 21.1 & (3) 15.8 & (1) 5.3 & & (1) 5.3 & \begin{tabular}{|ll} 
(8) 42.1 \\
\end{tabular} & $\begin{array}{|ll|}\text { (8) } 42.1 \\
\end{array}$ & (2) 10.5 & \\
\hline $\begin{array}{l}\text { Whole Grain } \\
\text { Pasta }\end{array}$ & & & (9) 47.4 & (6) 31.6 & (3) 15.8 & (1) 5.3 & & (1) 5.3 & (7) 36.8 & (10)52.6 & & (1) 5.3 \\
\hline $\begin{array}{l}\text { Sweets and } \\
\text { other Desserts }\end{array}$ & (4)21.1 & (4) 21.1 & (10)52.6 & & (1) 5.3 & & (1) 5.3 & (8) 42.1 & (7) 36.8 & (3) 15.8 & & \\
\hline
\end{tabular}


Food Frequency Questionnaire of Control Group BUCS: Live Well Participants from Pre-Evaluation and Post-Evaluation (n=18)

\begin{tabular}{|c|c|c|c|c|c|c|c|c|c|c|c|c|}
\hline \multirow[b]{2}{*}{ Items } & \multicolumn{6}{|c|}{ Pre-Evaluation } & \multicolumn{6}{|c|}{ Post-Evaluation } \\
\hline & $\begin{array}{l}\text { Daily } \\
\text { (n) } \%\end{array}$ & $\begin{array}{l}4-6 x / w k \\
\text { (n) } \%\end{array}$ & $\begin{array}{l}1-3 x / w k \\
\text { (n) \% }\end{array}$ & $\begin{array}{l}1 \mathrm{x} / \mathrm{mo} \\
\mathrm{(n)} \quad \%\end{array}$ & \begin{tabular}{l}
\multicolumn{2}{c}{ Never } \\
(n) $\%$
\end{tabular} & $\begin{array}{l}\text { Not } \\
\text { Sure } \\
\text { (n) \% }\end{array}$ & $\begin{array}{l}\text { Daily } \\
\text { (n) } \%\end{array}$ & $\begin{array}{l}4-6 x / w k \\
\text { (n) } \%\end{array}$ & $\begin{array}{l}1-3 \mathrm{x} / \mathrm{wk} \\
\text { (n) } \%\end{array}$ & $\begin{array}{l}1 \mathrm{x} / \mathrm{mo} \\
(\mathrm{n}) \quad \%\end{array}$ & $\begin{array}{l}\text { Never } \\
\text { (n) } \quad \%\end{array}$ & $\begin{array}{l}\text { Not } \\
\text { Sure } \\
\text { (n) \% }\end{array}$ \\
\hline Regular Sodas & (1) 5.6 & & (3) 16.7 & (2) 11.1 & (12)66.7 & & (1) 5.6 & (1) 5.6 & (2) 11.1 & (4) 22.2 & (10)55.6 & \\
\hline Diet Sodas $^{\mathrm{a}}$ & (1) 5.6 & & (2) 11.1 & (3) 16.7 & (11)61.1 & & (1) 5.6 & & (1) 5.6 & (4) 22.2 & (12)66.7 & \\
\hline Sweet Tea & & & (2) 11.1 & \begin{tabular}{|ll} 
(8) & 44.4 \\
\end{tabular} & (8) 44.4 & & & & (3) 16.7 & (8) 44.4 & (7) 38.9 & \\
\hline $\begin{array}{l}\text { Unsweetened } \\
\text { Tea }^{\text {a }}\end{array}$ & & & (1) 5.6 & (2) 11.1 & (14)77.8 & & & & (2) 11.1 & (2) 11.1 & (14)77.8 & \\
\hline $\begin{array}{l}\text { Energy Drinks } \\
\text { or Flavored } \\
\text { Waters }\end{array}$ & (1) 5.6 & (1) 5.6 & (1) 5.6 & (4) 22.2 & (9) 50.0 & (2)11.1 & (1) 5.6 & & (3) 16.7 & (4) 22.2 & (10)55.6 & \\
\hline $\begin{array}{l}\text { Alcoholic } \\
\text { Drinks }^{\mathrm{a}}\end{array}$ & & & (4) 22.2 & (4) 22.2 & (10)55.6 & & & (1) 5.6 & (2) 11.1 & (6) 33.3 & (8) 44.4 & \\
\hline Fruit & (9) 50.0 & (4) 22.2 & (3) 16.7 & $\begin{array}{|ll|}\text { (2) } & 11.1 \\
\end{array}$ & & & (8)44.4 & (1) 5.6 & \begin{tabular}{|ll} 
(5) 27.8 \\
\end{tabular} & $\begin{array}{|ll|}\text { (2) } 11.1 \\
\end{array}$ & (1) 5.6 & (1) 5.6 \\
\hline Green Salad & (2) 11.1 & (4) 22.2 & (7) 38.9 & (3) 16.7 & (1) 5.6 & (1) 5.6 & (1) 5.6 & (3) 16.7 & \begin{tabular}{|l}
$(12) 66.7$ \\
\end{tabular} & $\begin{array}{ll}\text { (2) } & 11.1 \\
\end{array}$ & & \\
\hline $\begin{array}{l}\text { French Fries } \\
\text { and/or Fried } \\
\text { Potatoes }\end{array}$ & (1) 5.6 & & (8) 44.4 & (6) 33.3 & (2) 11.1 & (1) 5.6 & & & (9) 50.0 & (6) 33.3 & (3) 16.7 & \\
\hline Vegetables & (8) 44.4 & (3) 16.7 & (6) 33.3 & (1) 5.6 & & & (5)27.8 & (7) 38.9 & \begin{tabular}{|l} 
(5) 27.8 \\
\end{tabular} & \begin{tabular}{|ll} 
(1) 5.6 \\
\end{tabular} & & \\
\hline Potato Chips & & (1) 5.6 & (8) 44.4 & (6) 33.3 & (3) 16.7 & & & (1) 5.6 & (5) 27.8 & (7) 38.9 & (4) 22.2 & (1) 5.6 \\
\hline $\begin{array}{l}\text { Baked } \\
\text { Crackers }\end{array}$ & & & (8) 44.4 & (5) 27.8 & (5) 27.8 & & & (1) 5.6 & (4) 22.2 & (9) 50.0 & (3) 16.7 & (1) 5.6 \\
\hline Baked Chips & & & (6) 33.3 & \begin{tabular}{|ll} 
(4) 22.2 \\
\end{tabular} & (8) 44.4 & & & (1) 5.6 & \begin{tabular}{|ll} 
(5) 27.8 \\
\end{tabular} & \begin{tabular}{|ll} 
(5) 27.8 \\
\end{tabular} & (5) 27.8 & (2) 11.1 \\
\hline White Bread & & (1) 5.6 & (3) 16.7 & (3) 16.7 & (9) 50.0 & (2)11.1 & & (1) 5.6 & \begin{tabular}{|ll} 
(3) 16.7 \\
\end{tabular} & $\begin{array}{ll}\text { (3) } & 16.7 \\
\end{array}$ & (10)55.8 & (1) 5.6 \\
\hline $\begin{array}{l}\text { Whole Grain } \\
\text { Breads }\end{array}$ & (4) 22.2 & (6) 33.3 & (3) 16.7 & (3) 16.7 & (2) 11.1 & & (3)16.7 & (4) 22.2 & (8) 44.4 & (1) 5.6 & (1) 5.6 & (1) 5.6 \\
\hline Pasta & (1) 5.6 & & (9) 50.0 & \begin{tabular}{|ll}
$(5)$ & 27.8 \\
\end{tabular} & (3) 16.7 & & & (2) 11.1 & \begin{tabular}{|ll}
$(6)$ & 33.3 \\
\end{tabular} & $\begin{array}{|ll|}(7) & 38.9 \\
\end{array}$ & (2) 11.1 & (1) 5.6 \\
\hline $\begin{array}{l}\text { Whole Grain } \\
\text { Pasta }\end{array}$ & (1) 5.6 & (1) 5.6 & (4) 22.2 & (7) 38.9 & (4) 22.2 & (1) 5.6 & & (1) 5.6 & (8) 44.4 & (6) 33.3 & (2) 11.1 & (1) 5.6 \\
\hline $\begin{array}{l}\text { Sweets and } \\
\text { other Desserts }\end{array}$ & (2) 11.1 & (2) 11.1 & (9) 50.0 & (5) 27.8 & & & (3)16.7 & (1) 5.6 & (10)55.6 & (4) 22.2 & & \\
\hline
\end{tabular}




\section{COURTNEY E. MCKINNEY}

Personal Data:

Education:

Professional Experience:

Publications:

Honors and Awards:
Date of Birth: November 13, 1989

Place of Birth: Houston, Texas

Marital Status: Single

Providence Academy, Johnson City, Tennessee

B.S. Foods, Nutrition, and Dietetics, Carson Newman College, Jefferson City, Tennessee 2011

M.S. Clinical Nutrition, East Tennessee State University, Johnson City, Tennessee 2013

Graduate Assistant, East Tennessee State University, Department of Allied Health Sciences, 2011-Present

Certified in Family and Consumer Sciences

Aryd, Marian. (2012). “Nutrition on the Net.” ETSU School of Graduate Studies Illuminated Magazine. Johnson City, TN: East Tennessee State University. pp. 14-16.

Roberts Dietetics Award, Carson-Newman College Braden Family and Consumer Sciences Award, Carson-Newman College 